\title{
Grid Connected PV System with MPPT Scheme Using Particle Swarm Optimization Technique \\ Adarsh Gupta ${ }^{a}$, Dr. Omveer Singh ${ }^{b}$
}

School of Engineering, Gautam Buddha university, Greater Noida, India ${ }^{a}$

School of Engineering, Gautam Buddha university, Greater Noida, India ${ }^{a}$

gadarsh79@gmail.com, soeee.ovs@gmail.com

\begin{abstract}
Electrical Energy has become one of the basic needs of an individual in this era. The requirement for energy is constantly rising day by day. The majority of electricity is presently generated by traditional thermal or hydro power plants. Renewable sources are very fashionable and popular for green energy and very widespread used nowadays. The electricity provided by photovoltaic (PV) systems is a very typical example of a clean renewable energy supply. When it comes to using PV as a renewable energy source, components like as an inverter are frequently utilized in this circumstance, and many ways have been presented to date to extract the most produced power from a PV system. This article recommends a $50 \mathrm{~kW} \mathrm{3-phase} \mathrm{grid-associated} \mathrm{system} \mathrm{with}$ different topologies such as, single stage and dual stage P\&O based MPPT techniques. A DC-AC converter, based on PWM for processing the energy generated by a solar array that is composed of SunPower SPR-230E-WHT-D PV modules with high power factor at any solar radiation. To improve the power quality, A control approach is presented in this article using Park's transformation (dq0 transformation) operators with for any scenario of solar radiation, a current control function in three phase grid-connected solar power generation with unity power factor is used. Harmonic components and reactive power provided by loads attached to the device can be compensated by the system and along with this a PSO based topology for MPPT to compare PSO with $\mathrm{P} \& \mathrm{O}$ technique and obtain best results.
\end{abstract}

Keywords: MPPT techniques, Particle Swarm Optimization, P\&O technique, Irradiation.

\section{Introduction}

Electrical Energy has become one of the basic needs of an individual in this era. The demand for electricity is steadily growing day by day. The majority of electricity is presently generated by traditional thermal or hydro power plants. Sustainable power source improvements, such as photovoltaic cells, are increasingly being proposed for power generation as concerns about ozone depleting substance outflow and other environmental difficulties grow.

The photovoltaic effect, discovered by Edmund Becquerel, a French scientist in 1839, allows solar radiation to be transformed into electricity. Sunlight is made up of photons, and when these photons enter a photovoltaic cell, they produce electrons and voltage through the solar cell's terminal, which can be used to power an electrical load. A PV cell is the most basic part of a PV device. PV cells are wired together in series to form modules, which are then wired together in series and parallel to make arrays. Solar insolation and ambient temperature affect the properties of a PV module.

\subsection{Energy Generation}

The fast expansion in industrialization, along with local consumers' reliance on energy, has resulted in a massive demand for electricity production. With the awareness of fossil fuel depletion and global warming, it is critical to introduce renewable, inexhaustible, and clean sources of electricity generation. Therefore, to 
encourage renewable energy generation government agencies are promoting various government policies and providing subsidies to generate power via these sources as a part of distributed generation. The two most common and efficient sources are wind energy and the solar energy.

The Fig1 shows that the renewable sources are only $28.4 \%$ of the total world requirement out of which solar is only $2.7 \%$. The current generation of electricity from solar in India was $36.9 \mathrm{GW}$ as of 30 November 2020. But none of the technology till now is independent capable of fulfilling the requirements of the consumers. Therefore, the concept of integrating or connecting the distributed generation to the grid evolved so that the deficient power can be fed to the grid through them.

The DG's were made even more attractive to local consumers of the distribution network by the implementation of the smart meters. With the combinational use of both the smart meters and the DG the consumers can also become producers of electricity at the same time. Solar energy being an easily available free source in nature is always a priority for the research workers. It plays a vital importance as it is globally available and flexible in terms of the plant size and also because it can fulfill the requirements of different consumers since it offers both on-grid and off-grid options.

In the realm of solar photovoltaic systems, power electronics plays an important role. The efficiency of a solar PV system is mostly determined by power electronics-based equipment such as inverters and converters. The adoption of these upgraded devices can result in an improvement in conversion efficiency as well as a reduction in losses. Improvements in the technology of these power electronics devices may lead to new solar photovoltaic systems that are both cost effective and efficient.

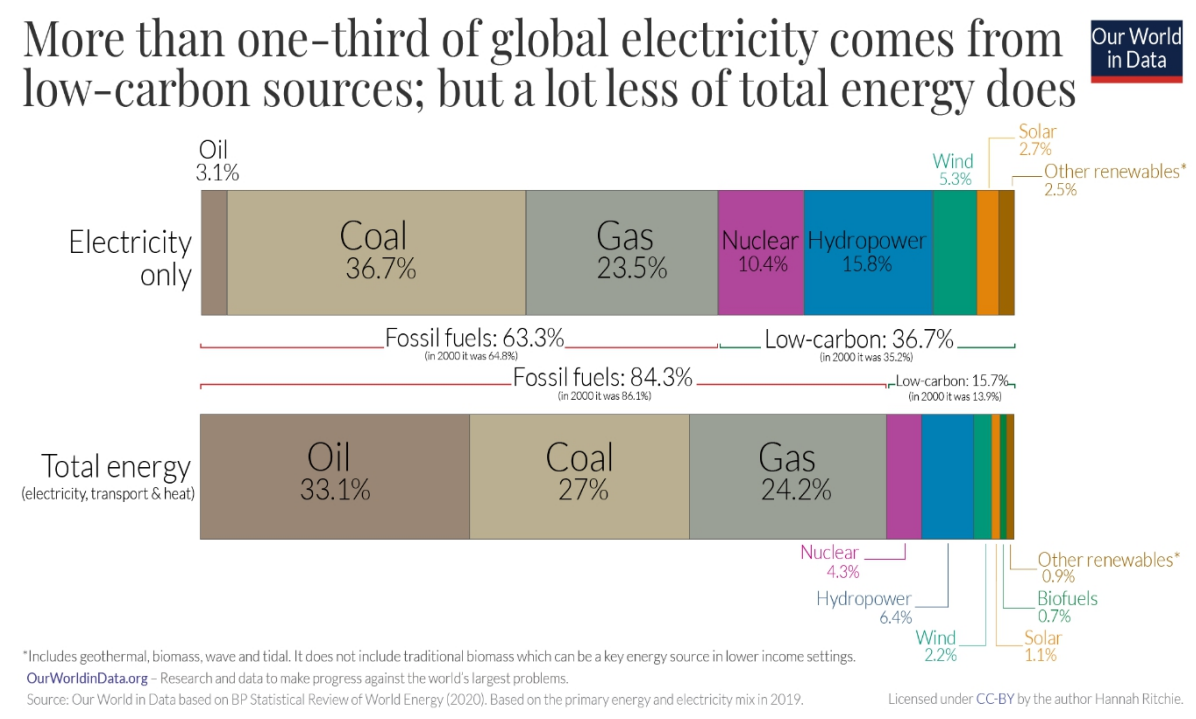

Fig 1: World Electricity Production by Source 2019. [1] 


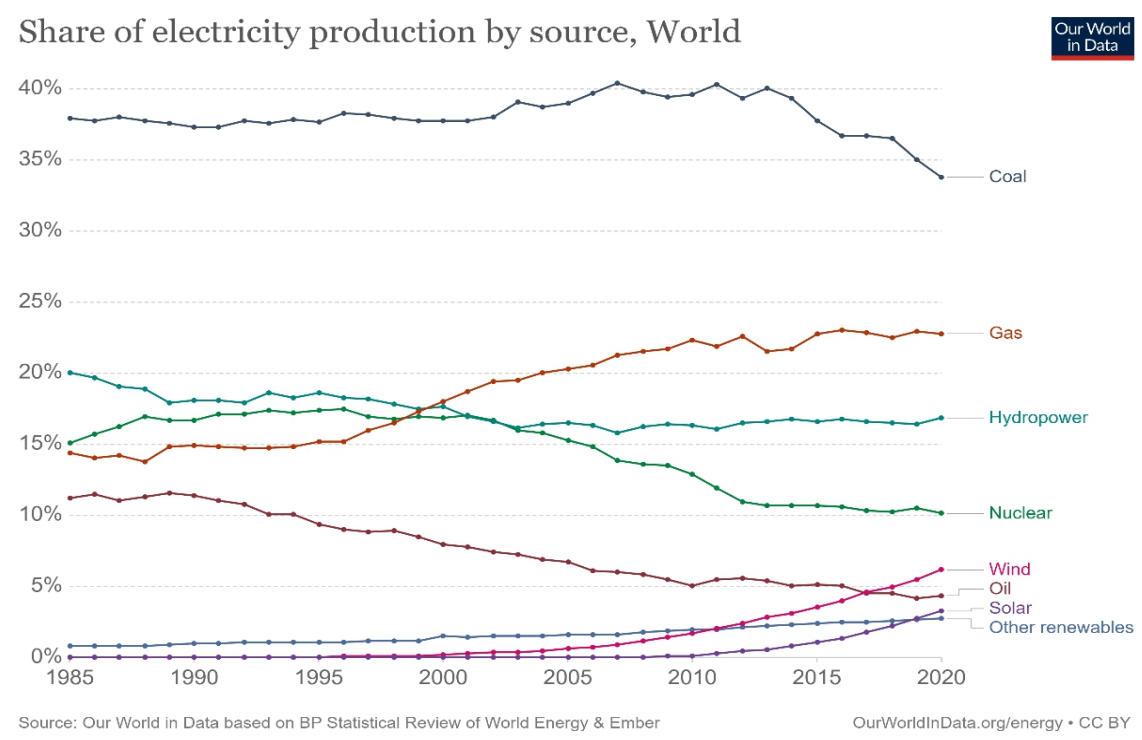

Fig 2: World Electricity Production by Source since 1985. [1]

The expanding request of electrical Energy and expanded ozone depleting substances have spurred power utilities to coordinate conveyed age (DG) to the circulation organize. The breeze and sun powered photograph voltaic (PV) are generally famous DG assets which can be worked in detached or framework associated mode relying on the necessity.

Low-carbon sources account for around 16 percent of global energy (15.7 percent, to be exact) that is, nuclear energy and renewables together. Despite the fact that many people use these phrases interchangeably, energy and electricity are not the same thing. Electricity (sometimes known as "power") is just one component of total energy production, which also includes heating and transportation. What percentage of our electricity is generated from low-carbon sources?

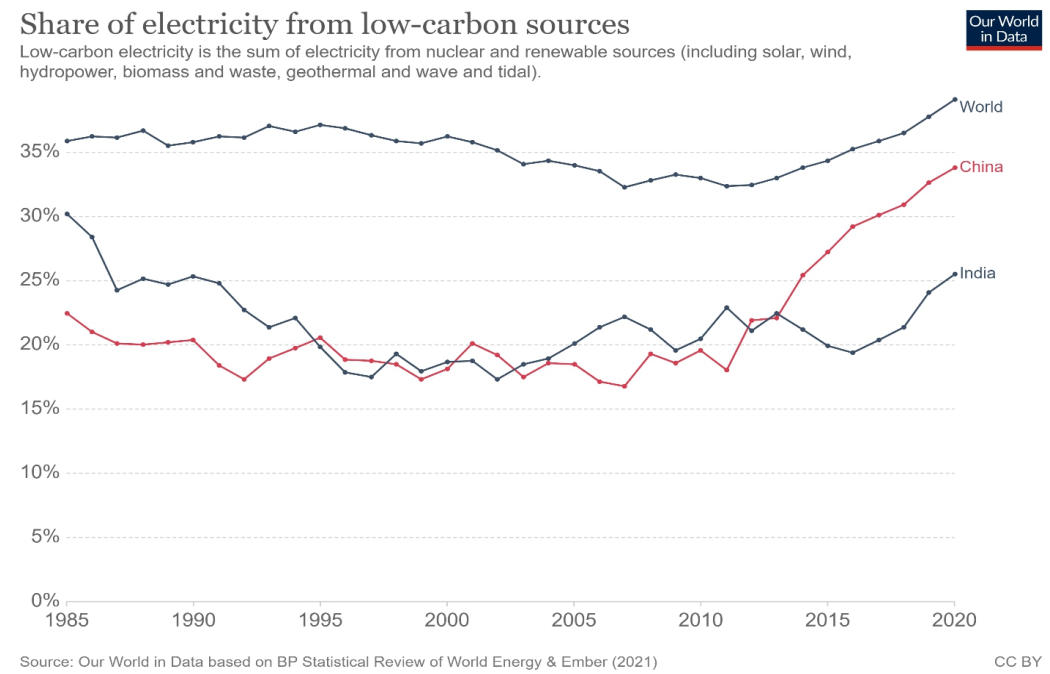

Fig 3: Electricity Production comparison by Source with India and China since 1985. [1]

Low-carbon sources account for $37 \%$ of worldwide electricity production. The percentage of world electricity generation that comes from nuclear or renewable energy sources like solar, wind, hydropower, wind and tidal, as well as some biomass, is shown in the graph. In 2019, 36.7 percent of our electricity was low-carbon around the world. More over a third of the population. The remaining two-thirds of the energy 
comes from fossil fuels, namely coal and natural gas.

This is more than double the percentage of nuclear and renewable energy in the whole energy mix, which is only 15.7 percent. Regrettably, the share of electricity generated from low-carbon sources has remained virtually static since the mid-1980s. In reality, during the early 2000 s, this percentage decreased. We'll see in the next section that development was modest because nuclear output fell at a time when renewables were increasing.

\subsection{The Need of Renewable Energy}

Tidal wave, solar, rainfall, geothermal energy, and wind are all examples of alternative energy sources. These resources can be replenished spontaneously and will never run out. In contrast to these renewable commodities, which are inexhaustible in nature, the main source of energy these days comes directly or indirectly from fossil fuels, which are constantly depleted of the earth's storage capacity. People all over the world have been looking for non-conventional energy sources to meet their critical energy needs for a long time as time has passed. With an increasingly rising population and increased use of fossil fuels, exposure to the atmosphere has increased as well, necessitating the adoption of Clean and Green Mechanisms by countries all over the world. The sustainable and pollution-free use of green energies is what has drawn the current world, and as a result, a significant amount of money is being invested in harvesting these commodities.

To improve the renewable strength utility in cutting-edge strength machine, authorities organizations everywhere in the globe are introducing new schemes and policies. Solar photovoltaic strength being a famous and hooked up generation for strength technology withinside the class of renewable strength is nowadays mushrooming. People everywhere in the international are awaked with the aid of using the significance and blessings of sun photovoltaic strength machine. But the sun strength itself isn't enough to satisfy the requirement of the consumers. So subsequent viable answer emerges is the grid related machine. In grid related machine, the requirement of strength is being crammed with the aid of using each an limitless supply of strength referred to as grid and sun photovoltaic strength. Thus, the evolution of grid related photovoltaic machine evolved.

By 2022, the Indian authorities has set a lofty purpose of producing a hundred seventy five GW of polluting-loose electricity. According to the Ministry of New and Renewable Energy (MNRE), India's anticipated renewable strength capability is at $900 \mathrm{GW}$, with $20 \mathrm{GW}$ coming from small hydro, $102 \mathrm{GW}$ from wind strength (eighty meter mast height), $25 \mathrm{GW}$ from biomass, and $750 \mathrm{GW}$ from sun strength (primarily based totally on three percentage wasteland). As a results of the preceding facts, alternative energy has emerged as a significant supply of inexperienced energy among renewable energy, which is able to create history for the country' development and propel it to new heights within the Indian power industry. 


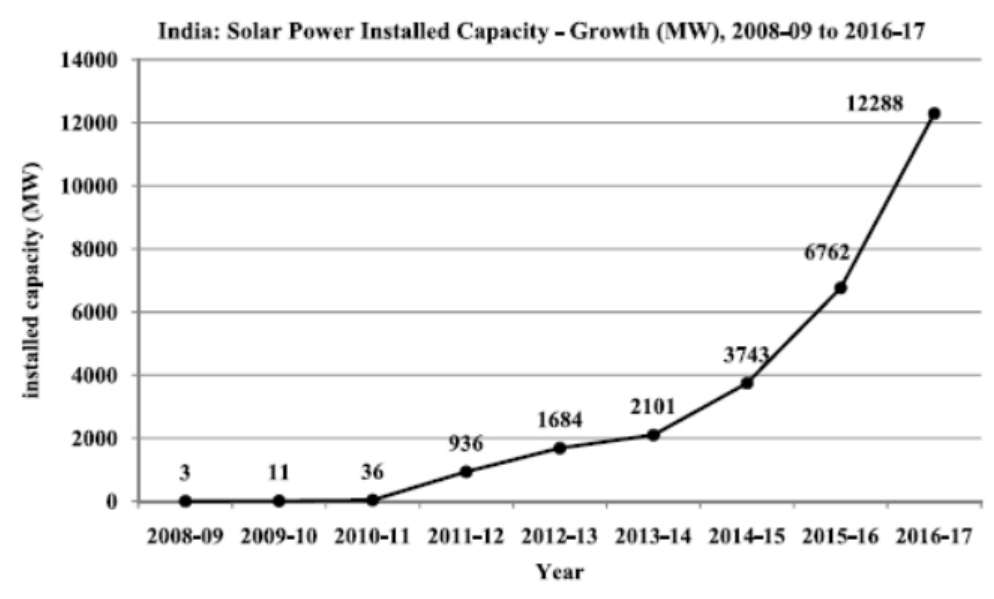

Fig 4: Advancement of Solar Power in India.

\subsection{Solar power}

Since conventional energy supplies are in short supply, the increasing power demand of everyday life cannot be met solely with them. Renewable energy sources have become more common as a complement to traditional systems in order to satisfy and energy demands. The primary vitality factors used in this respect are inexhaustible sources such as sun-oriented vitality and wind vitality. The consistent utilization of non-renewable energy sources has radically influenced nature exhausting the biosphere and causing an unnatural weather change. Collecting Solar vitality is conceivable in light of it's bounteously accessibility. Sun-based vitality can be a stand-alone producing unit or a lattice-connected producing unit, depending on the availability of a nearby framework. Because rural regions have limited access to infrastructure, renewable energy sources are used to their full potential. Another advantage of solar energy is its portability, which allows it to be utilized wherever it is needed. The current energy crisis may be alleviated by efficiently producing power from incoming solar radiation. Power transmission technologies have been greatly simplified in recent years. To meet the high-power requirement, advancements in 1power electronics and material technology have aided technicians in developing extremely compact yet efficient systems. The only drawback of these devices being the higher power density.

\subsubsection{Representation of Grid tied PVScheme}

Electronic systems inverters based on semiconductor devices are employed in grid-tied PV systems for power transfer, connectivity, and control management. In grid synchronization, the system's steady state monitoring and management strategy are critical. For optimal grid synchronization, the inverter's output should be sinusoidal. As a result, a photovoltaic system necessitates an inverter with a high power factor, reduced THD, and quicker dynamics, as well as a grid inverter management technique that guarantees that electricity is delivered into the grid in the smallest possible proportion while maintaining phase with the grid voltage.

The illustration of a grid-connected PV system is shown in Figure 5. The block diagram depicts the very simple concept and idea that led to the creation of this project. Right now, a huge portion of power is created from non-renewable energy sources, particularly coal because of its low costs. 


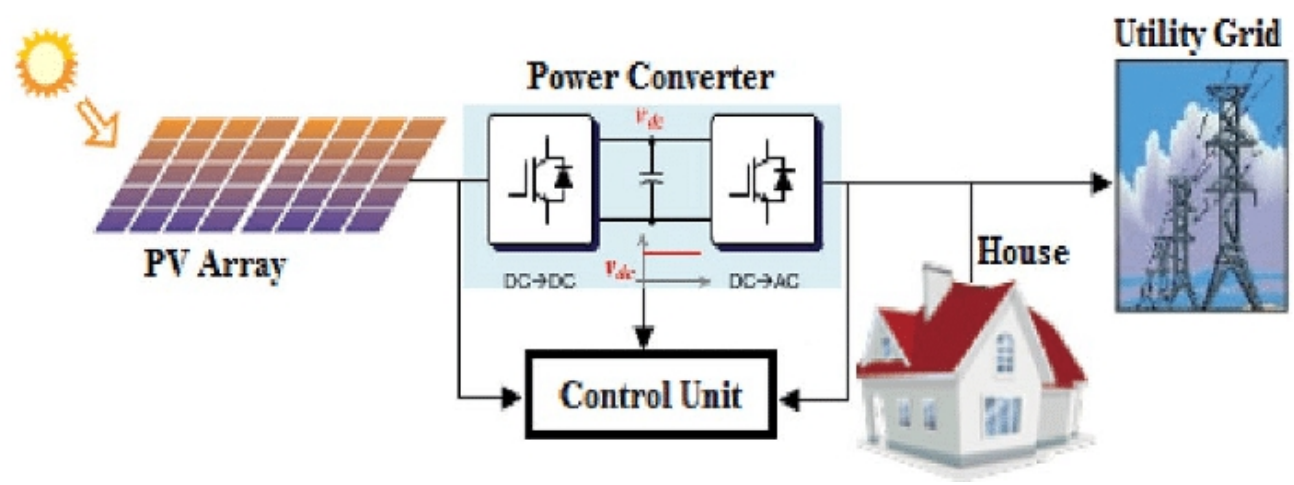

Fig 5: A grid-tied PV system is depicted.

Notwithstanding, the expanding utilization of petroleum products represents a noteworthy bit of natural contamination and ozone harming substance outflows, which are viewed as the primary explanation for the an unnatural weather change. To beat the issues related with age of power from petroleum derivatives, sustainable power sources can be taken part in the vitality blend. One of the sustainable strength assets that may be applied because of this for present is the mild gotten from the sun. This mild may be modified over to smooth strength thru the photovoltaic procedure. The usage of photovoltaic (PV) frameworks for strength age started out withinside the seventies of the 20 century and is at gift turning into quick across the world. Indeed, several institutions expect a superb destiny for those frameworks.

There are various factors affecting the solar photovoltaic output power and so it becomes very essential to analyze and forecast their impacts so that optimization of the network characteristics and extraction of the power to great extend can be done accordingly. Mostly the photovoltaic system suffers from the issues of weather conditions and partial shading related concern depending upon the site of installation. The primary disadvantages of a solar photovoltaic system are the huge area required for electricity generation and its reliance on environmental conditions. Also, the consumers of the distribution network always have a financial issue and the concern regarding their benefits towards their investment.

Meanwhile, the Grid Connected PV (GPV) system has recently become a more important source of electricity as well as a vital component of the power grid's generating network. Researchers see themselves confronted with considerable problems in single-phase and three-phase GPV systems: maximum power consumption from photovoltaic modules, rapid power fluctuations and regular fluctuations in power, effects on the network quality, in particular on voltage harmonics and current, current return and mismatching between PV output and network demand are all part of it the challenges. As opposed to single-phase systems, three-phase GPV generation systems are widely preferred in high power applications because of their ability to produce near-continuous power flow and eliminate unnecessary grid current imbalances. Developing a GPV Generation System PV researchers create an efficient and intelligent grid-connected PV generation system with an optimization scheme based on the specialization of parameters in each of the individual components of the system as well as identifiable challenges. The GPV generation system is shown in Figure 6. 


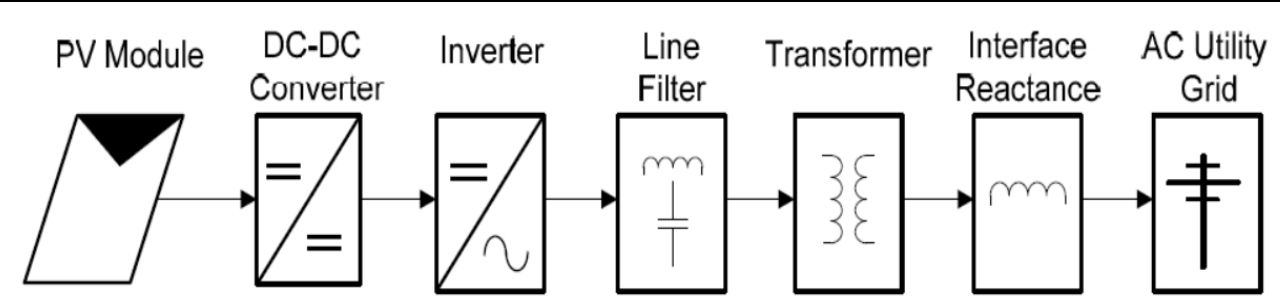

Figure 6: The GPV generating mechanism is depicted in a single line diagram.

PV modules come in a variety of shapes and sizes, and they may be divided into numerous categories. Silicon PV modules, both monocrystalline and polycrystalline, are well-established advanced technologies that presently dominate the commercial PV market. They are the first generation of PV technologies, with a conversion efficiency of more than $20 \%$ recently attained. The second generation of PV systems are thin-film systems. Thin-film PV modules are less efficient than the previous generation, but they are significantly cheaper to manufacture.

Although the maximum photovoltaic efficiency of four-digit hybrid photovoltaic technology (UNSW) exceeds $40 \%$, its structure is very complex, and calculations are made for concentrated radiation. Although the initial cost can be high, using high performance PV modules has the benefit of minimizing active assembly area, material use, and device balance.

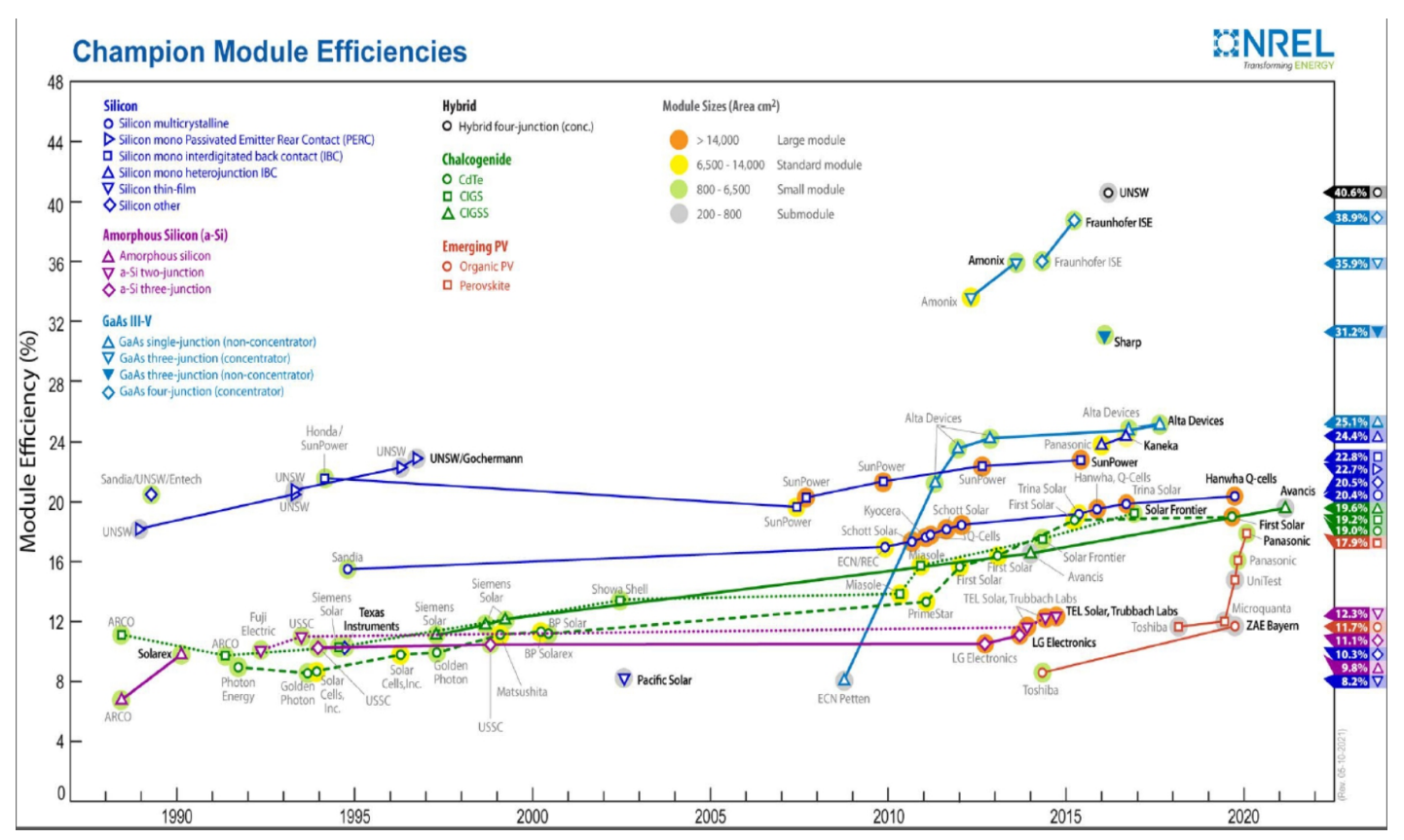

Figure 7: Efficiency chart for different kind of Solar Modules. [2]

\subsection{Literature Review}

This section contains a literature review of the numerous modules in this research. Several books and journal articles on grid-connected PV systems using different techniques and methods were examined. These studies form the foundation of this research project.

K.H. Hussein et al. [3] introduced a new Maximum Power Point Tracking (MPPT) algorithm that compares the continuous and instantaneous conductivity of the material of the PV array to monitor the 
Maximum Power Operating Point (MPOP). The author of this paper discovered some flaws in the Perturb and Observe approach and demonstrated that the Incremental Conductance algorithm effectively monitored the MPOP. The work was carried out by both simulation and graphs.

Villalva et. al. [4] explained the current ecological and climate conditions, particularly sun-oriented irradiance, temperature, and wind speed, are reported and analyzed in his paper. At around the same time, the prompt information from the plant including PV module temperature, electricity, current, and voltage are provided timely. The power reduces as the surrounding temperature rises. Another Fuzzy Logic-based approximation is proposed to greatly reduce the power decline under halfway concealing conditions.

Sridhar R. [5] proposed the display and reconstruction of a photovoltaic model. The PV exhibit is displayed, and its voltage current characteristics, as well as the strength and voltage values, are recreated, taking into account the temperature and sun's irradiance. This allows the PV framework's components to be successfully recreated and advanced. The natural components have an effect on the yield qualities of a PV exhibit, and the transformation productivity is poor. As a result, a maximum power point monitoring (MPPT) protocol is required to monitor the maximum potential in order to increase the generated vitality.

E. Vartiainen et. al. [6] explained the radiant irradiance on a sloping or leaning in a particular direction surface is usually estimated from hourly flat irradiance estimations using a slant irradiance model It is also possible to calculate the slant irradiance by using a sky brilliance model to include the sky brilliance conveyance. Five slant irradiance models and six sky dissemination models are compared in this article, as well as hourly irradiance estimations on 24 slanted surfaces.

H. Fujita et al. [7] propose a solitary pulse width modulation technique to demonstrate how a three-stage sun-powered force conditioner works. In each PWM-transporter cycle, the proposed pulse width modulation switches on or off one of the three-stage legs. In comparison to a traditional three-stage PWM approach, the proposed method makes it possible to reduce the usual exchanging recurrence by a factor of three and reduce the exchanging power misfortune to $1 / 3$ or less.

Santosh S. Raghuwanshi, Kamlesh Gupta et. al. [8] proposes and suggest a photovoltaic (PV) interface model with associated controllers. In the MATLAB/SIMULINK computer, the reproduction model is developed. A PV exhibit, a dc-dc converter, a PWM dependent voltage source inverter, and a channel are the basic components of the single stage framework linked PV framework. The most intense force point following (MPPT) measure was used to ensure the PV framework's high proficiency. Reproduction studies demonstrate that as the sun's irradiance increases, so does the PV exhibit yield capacity and, as a result, the PQ.

Pratima Mohanty et al. [9] In their article, they introduced several MPPT strategies and suggested some new ones. His paper compares the efficiency and study of MPPT techniques used in solar PV generation systems under various temperature and irradiation level pressures, as well as in the direction of successful solar cell usage that can be overcome using MPPT techniques. In his article, he discusses $\mathrm{P} \& \mathrm{O}, \mathrm{INC}$, and constant voltage topologies and control schemes.

S. Yuvarajan et al [10] Based on the open circuit voltage and short circuit current of photovoltaic 
modules, a fast and reliable MPPT (Maximum Power Point Tracking) algorithm for photovoltaic modules is proposed. The algorithm is created using mathematical equations that determine the non-linear characteristics of the VI PV panel. The MPPT algorithm is suitable for many situations, including varying degrees of insulation, temperature, and wear. The algorithm was tested in MATLAB, and the results are very similar to the theoretical values in a wide range of temperature and light. In the light intensity and temperature displayed by commercial photovoltaic modules, the overall difference in peak performance is less than $1.5 \%$. The full version of the MPPT algorithm has been released. This algorithm has proven to be faster than other MPPT algorithms (such as z-circuit). Closing).

Prof. Dr. Ilhami Colak, et al. [11] used The Matlab Simulink real-time analysis tool is used to simulate three different solar parks, each with a power of $15 \mathrm{~kW}$. The full power point tracking (MPPT) algorithm is used to convert energy into the interference and observation (P\&O) structure of each transducer. On the DC bus, the converter is connected in parallel with the interface transformer (IPT). This voltage is applied to a full-bridge inverter, which generates a three-phase AC voltage at the output and operates according to a sinusoidal pulse width modulation (PWM) scheme.

Ma T. et al. [12] described a novel hypothetical model that struck a good balance between precision and simplicity. In Matlab, a model for determining sunlight-based photovoltaic (PV) module parameters was developed, and the model was then fitted to exploratory I-V trademark bends of a PV module/string/cluster. For the model, only a few sources of data are needed, which can be found on the creator datasheet. The appearance of a PV module/string/cluster at any sun-based irradiance and module cell temperature can be easily recreated with this recently developed model.

Jaydeep et. al. [13] The value of electricity is explained. Also demonstrates how to reenact a network-connected solar-powered photovoltaic system using the Pvsyst software package, and how to evaluate their presentation. The presentation proportion as well as the various types of strength misfortunes (temperature, inner system, and effect hardware) are calculated. The feasibility of introducing a 1 MW sun-generated photovoltaic (PV) power plant in the geographical region of Shapur, Gujarat, is considered based on the findings.

Kamlesh Gupta et. al. [14] introduces a photovoltaic (PV) system model with associated controllers. In the MATLAB/SIMULINK computer, the reproduction model is developed. A PV exhibit, a dc-dc converter, a PWM dependent voltage source inverter, and a channel are the basic components of the single stage framework linked PV framework. The most intense force point following (MPPT) measure was used to ensure the PV framework's high proficiency. Reproduction studies demonstrate that as the sun's irradiance increases, so does the PV exhibit yield capacity and, as a result, the PQ.

Calais et. al. [15] introduces a study of the development of a single-stage grid-connected photovoltaic (PV) frame with an output power of up to $5 \mathrm{~kW}$ and an overview of advanced inverter technology in Europe. The information includes specifics on the topologies that are commercially available, as well as the exchanging gadgets that are used, as well as the associated exchanging speeds, proficiency, value trends, and slice of the pie. Finally, the paper depicts problems relating to the progression of relevant global market indicators affecting PV inverter innovation. 
Mohamed Azab et. al. [16]. proposed a new MPPT algorithm for solar modules. The algorithm determines the maximum power VF point. The calculated maximum power is used as a reference (set value) for the control system. The power output of the Buck helicopter is controlled by the hysteresis range on/off power regulator, and the MPPT algorithm is used to ensure that the PV module is still running at its maximum rated power. The suggested algorithm differed from other methods in that it was used to manage the power drawn from the PV directly. The proposed MPPT has a number of benefits, including simplicity, fast convergence, and independence from PV array characteristics. The algorithm was put to the test in a variety of scenarios. The obtained results demonstrated that the MPP could be monitored even though the irradiation level was suddenly changed.

Yang Du et al [18] investigated a battery-integrated boost converter for module-based series attached photovoltaic (PV) systems. Each PV module is equipped with a battery and a DC/DC converter. Full power point monitoring (MPPT) and battery charging are achieved by the converter. When applied to a module-based series-connected PV device, the proposed converter will retain string voltage while eliminating the need for an additional voltage amplification level. The power flow equations were determined using a steady-state analysis of the converter. Three advantages were identified as compared to the traditional series linked boost converter. Simulation of laboratory prototype and experimental findings were discussed.

S. C. Kaushik et al. [19] suggest an analysis of inverters that use solar irradiation through a simple system that includes a lift converter and a single-stage sine wave support inverter. The suggested architecture embraces the low voltage of a photovoltaic (PV) cluster by charging the battery with a dc-dc help converter. For high efficacy, a most drastic force point following conspiracy is suggested with arrangement association of a dc-dc converter contribution with a PV board. This approach increases the productivity of vitality change.

Wafa Hayder et al. [20] proposed an idea on the development and analysis of a novel maximum power point tracking (MPPT) control system are discussed in his article, which is tested under a variety of environmental circumstances. Based on Particle Swarm Optimization, a new MPPT approach for solar systems has been developed (PSO). The innovative Improved Particle Swarm Optimization (IPSO) algorithm is put to the test in a series of simulations that consider diverse system reactions including voltage, current, and power. The suggested IPSO algorithm's performance has been finished and compared to the results of well-established methods used in the literature, which demonstrate that the new IPSO algorithm has a greater accuracy.

Ashish Pandey et. al. [17] Because of constantly changing environmental conditions, the author and the other members explain the shortcomings of the Perturb \& Observe (P\&O) approach. The drift was reduced by measuring the entire pattern in a power versus voltage curve using a variable step-length algorithm. A comparison of various MPPT algorithms can be found in Table 1. The two most critical factors to consider when selecting MPPT algorithms are convergence speed and implementation complexity. Table 1 summarizes the details. 
International Journal of Intelligent Communication, Computing and Networks

Open Access Journal (ISSN: 2582-7707)

https://doi.org/10.51735/ijiccn/001/32

\begin{tabular}{|c|c|c|c|c|c|c|c|}
\hline MPPT Technique & $\begin{array}{l}\text { PV Array } \\
\text { Dependent? }\end{array}$ & $\begin{array}{l}\text { True } \\
\text { MPPT? }\end{array}$ & $\begin{array}{l}\text { Analog or } \\
\text { Digital? }\end{array}$ & $\begin{array}{l}\text { Periodic } \\
\text { Tuning? }\end{array}$ & $\begin{array}{l}\text { Convergence } \\
\text { Speed }\end{array}$ & $\begin{array}{l}\text { Implementation } \\
\text { Complexity }\end{array}$ & $\begin{array}{c}\text { Sensed } \\
\text { Parameters }\end{array}$ \\
\hline Hill-climbing/P\&O & No & Yes & Both & No & Varies & Low & Voltage, Current \\
\hline IncCond & No & Yes & Digital & No & Varies & Medium & Voltage, Current \\
\hline Fractional $V_{O C}$ & Yes & No & Both & Yes & Medium & Low & Voltage \\
\hline Fractional $l_{\mathrm{SC}}$ & Yes & No & Both & Yes & Medium & Medium & Current \\
\hline Fuzzy Logic Control & Yes & Yes & Digital & Yes & Fast & High & Varies \\
\hline Neural Network & Yes & Yes & Digital & Yes & Fast & High & Varies \\
\hline RCC & No & Yes & Analog & No & Fast & Low & Voltage, Current \\
\hline Current Sweep & Yes & Yes & Digital & Yes & Slow & High & Voltage, Current \\
\hline DC Link Capacitor Droop Control & No & No & Both & No & Medium & Low & Voltage \\
\hline Load $I$ or $V$ Maximization & No & No & Analog & No & Fast & Low & Voltage, Current \\
\hline$d P / d V$ or $d P / d l$ Feedback Control & No & Yes & Digital & No & Fast & Medium & Voltage, Current \\
\hline Array Reconfiguration & Yes & No & Digital & Yes & Slow & High & Voltage, Current \\
\hline Linear Current Control & Yes & No & Digital & Yes & Fast & Medium & Irradiance \\
\hline$I_{M P P} \& V_{M P P}$ Computation & Yes & Yes & Digital & Yes & $\mathrm{N} / \mathrm{A}$ & Medium & $\begin{array}{l}\text { Irradiance, } \\
\text { Temperature }\end{array}$ \\
\hline State-based MPPT & Yes & Yes & Both & Yes & Fast & High & Voltage, Current \\
\hline OCC MPPT & Yes & No & Both & Yes & Fast & Medium & Current \\
\hline BFV & Yes & No & Both & Yes & $\mathrm{N} / \mathrm{A}$ & Low & None \\
\hline LRCM & Yes & No & Digital & No & $\mathrm{N} / \mathrm{A}$ & High & Voltage, Current \\
\hline Slide Control & No & Yes & Digital & No & Fast & Medium & Voltage, Current \\
\hline
\end{tabular}

Table 1: Comparison between various MPPT algorithms.

\section{Modeling of the System}

This chapter gives a brief idea of various segments of a photovoltaic framework and endeavors to feature ongoing exploration exercises in the field of photovoltaics.

\subsection{PV array}

In Fig. 10, A photovoltaic panel is shown, which captures sunlight using PV cells. Layers of silicon $\mathrm{p}$ and silicon n make up PV cells. Light of a certain wavelength ionises the silicon atoms and the internal field between positive and negative charges inside the photovoltaic device. There is better contact between the atoms when there is a high irradiation, which results in a high generation of potential difference. When an incoming photon has energy larger than the bandgap of the semiconductor component element, a solar cell is primarily a p-n junction diode that produces charge carriers. A photovoltaic module is an interconnection of modules made up of many PV cells linked in series and parallel to obtain the necessary power, whereas a photovoltaic array is an interconnection of modules made up of many PV cells connected in parallel or series to obtain the desired power. The model is best fit for the empirical conditions since it includes a series and parallel resistance as well as the observation of the terminal voltage.

The electric qualities of the PV cell rely predominantly upon the irradiance got by the cell and the cell temperature. Figure 8 shows the electrical attributes of the cell at various degrees of the irradiance and steady temperature. Plainly the change in irradiance strongly affects the short out current and yield intensity of the cell, however unimportant impact on the open-circuit voltage. 


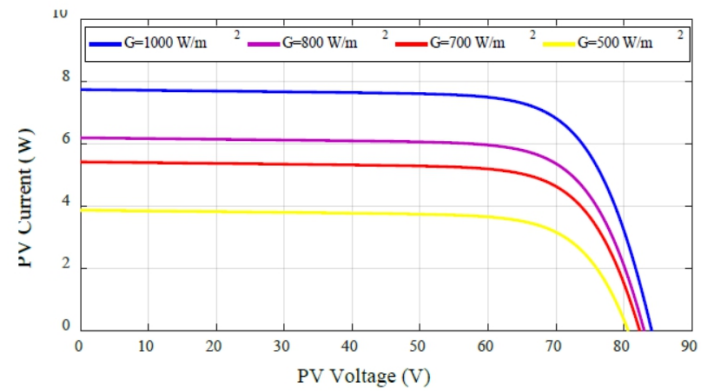

(a)

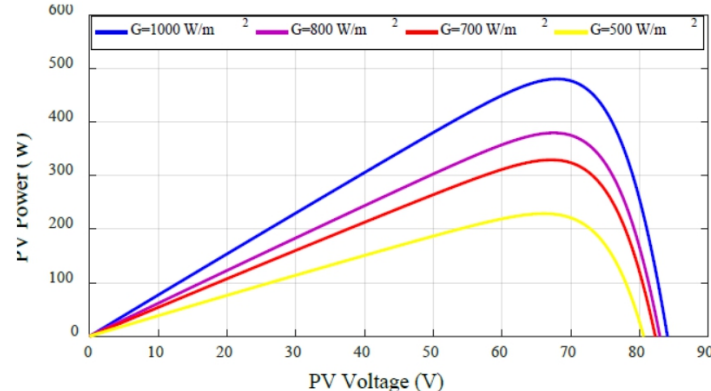

(b)

Fig 8: PV Cell Characteristic Graph at Variable Irradiance and Constant Temperature

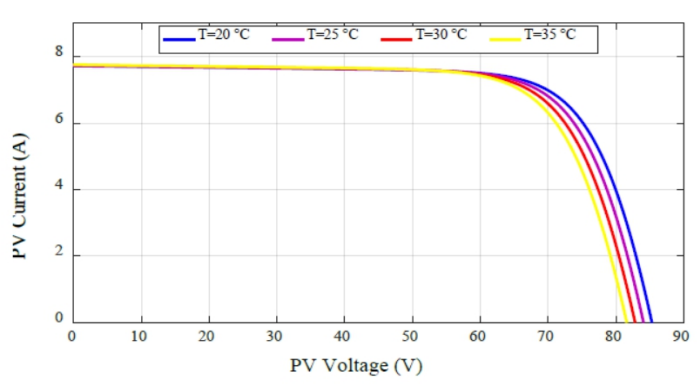

(a)

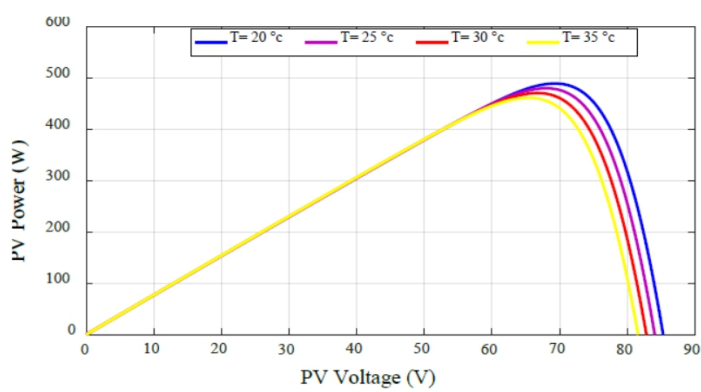

(b)

Fig 9: PV Cell Characteristic Graph at Variable Temperature and Constant Irradiance.

Then again, Figure 9 shows that the change in temperature at consistent irradiance strongly affects the open-circuit voltage and yield intensity of the cell, yet unimportant impact on the short out current. Generally sun based cells are associated in arrangement to shape a sun based module and modules are at that point associated in arrangement to shape a string. At last, the strings are associated in corresponding to frame PV exhibit. The quantity of modules in each string is determined by the required voltage level of the exhibit. Then again, the quantity of strings is determined agreeing to the necessary current rating of the cluster. Most PV clusters have a force diode, called sidestep diode, associated in corresponding with every individual module or various modules.

The capacity of this diode is to direct the present when at least one of these modules are harmed or concealed. Another diode, called blocking diode, is generally associated in arrangement with each string to forestall switch current stream and secure the modules. 

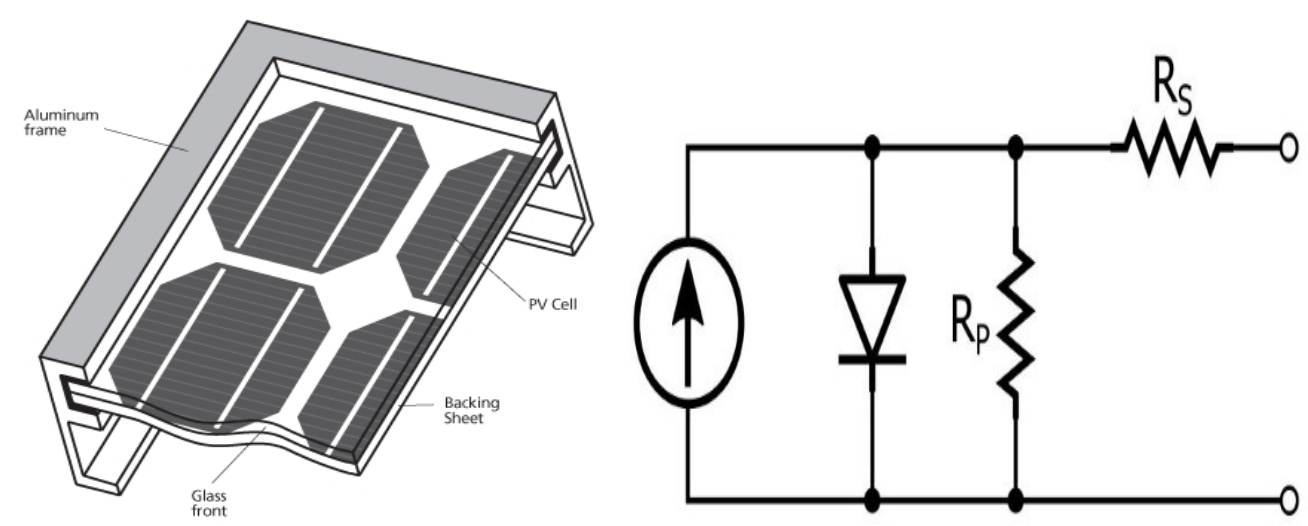

Fig 10: Equivalent Circuit of PV Cell

The basic equation of a single solar cell is:

$$
I=I_{p v}-I_{0}\left[e^{(q V / a k T)}-1\right]
$$

"I" is the net current of a single solar cell, "Ipv" is the total current generated by solar radiation, "I0" is the reverse saturation current or diode leakage current, and " $\mathrm{a}$ " is the ideal diode ratio, that is, necessary Adjust to compare the PN junction of the solar cell with the measured value; " $\mathrm{T}$ " is the Kelvin temperature of the diode, "q" is the electronic charge, and $\mathrm{k}$ is the Boltzmann constant. Equation (1) is not sufficient to describe the characteristics of actual solar cells. By adding series and parallel resistors and observing the terminal voltage, the model can better adapt to empirical conditions.

$I=I_{p v}-I_{0}\left[\exp \left(\frac{V+R_{s e r} I}{V_{t} a}\right)-1\right]-\frac{V+R_{\text {ser }} I}{R_{p e r}}$

"Rser" represents the overall series confrontation of resistance for all connected solar cells, "Rper" represents the entire parallel confrontation of resistance for all connected solar cells, and "Vt" is the terminal voltage, which can be calculated as "Vt $=\mathrm{kT} / \mathrm{q}=\mathrm{T} / 11600$ "and" $\mathrm{V}$ " is the voltage at the solar cell combination terminal, "Rser" is generated by the contact resistance between the connection terminal and the solar cell, and "Rper" is generated by the leakage current of the pn junction. (2) It can be changed according to the number of parallel and series combinations of solar cells that make up the photovoltaic system. Increasing the number of batteries in the module will increase the voltage and increasing the number of batteries in parallel in the module will increase the photovoltaic field current. In this paper a PV array using SunPower SPR-230E-WHT-D was used to validate the proposed methodology. The SunPower SPR-230E-WHT-D module specifications are showing in Table 2.

\begin{tabular}{|l|l|}
\hline Maximum Power (in watts) & $230.04 \mathrm{~W}$ \\
\hline Maximum Power Voltage (in volts) & $40.5 \mathrm{~V}$ \\
\hline Maximum Power Current (in Amps) & $5.68 \mathrm{~A}$ \\
\hline Open Circuit Voltage $\left(\mathrm{V}_{\text {oc }}\right)$ & $48.2 \mathrm{~V}$ \\
\hline
\end{tabular}




\begin{tabular}{|l|l|}
\hline Short Circuit Current $\left(\mathrm{I}_{\mathrm{sc}}\right)$ & $6.05 \mathrm{~A}$ \\
\hline Cells per Module (Ncell) & 72 cells \\
\hline Temperature coefficient of $\mathrm{V}_{\mathrm{oc}}(\% /$ degree $)$ & $0.31 \mathrm{c}$ \\
\hline
\end{tabular}

Table 2: Specification of Used PV module while Simulation

\subsection{Different Configuration of PV System}

The PV systems can be classified into two types, i.e., stand-alone and grid-connected PV system. There are numerous PV system configurations in the literature to improve the efficiency and performance of the PV system. The general PV system configurations of stand-alone PV system with DC and AC load and grid connected system are shown in Fig.11. Stand-alone PV systems can provide power supply to the load either from the PV source or battery or both, depending on the load requirement and available PV power. Grid connected PV system has the advantage of reduction of losses in the distribution line and the transformer. However, grid connected PV system is tedious in terms of grid synchronization. Thus, depending on the type of application and necessity, proper architecture has to be chosen for the design of the PV systems.

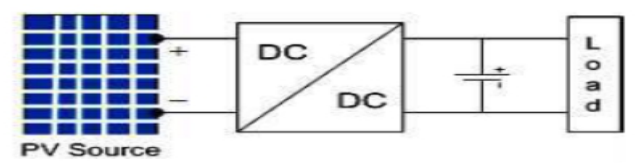

(a)

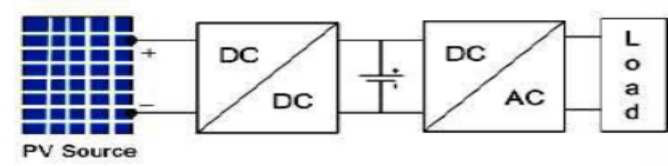

(b)

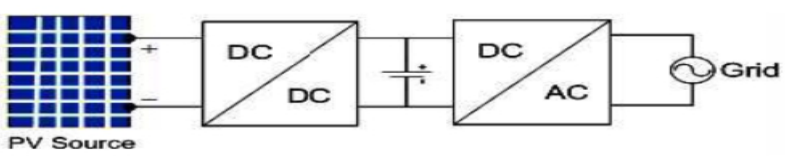

Figure 11: Different architectures of PV systems (a) stand-alone PV system with DC load. (b) stand-alone PV system with AC load. (c) grid connected PV system

\subsection{INVERTER}

Inverters with a single stage might be square-wave or PWM inverters. The square wave kind is the least unexpected framework for converting $\mathrm{DC}$ to $\mathrm{AC}$; nonetheless, it meets low repetition noises, which makes filtering through the cacophony hold these songs to return to the transformer's fundamental side difficult. Because the PWM inverter regulates the sounds to be higher than the necessary (line) repeat, the inverter's isolating requirement is reduced.

\subsubsection{Inverter Classification}

Figure 12 summarizes the broad categorization of Multifunctional Inverters (MFI) established on circuit power formation. 
Inverter classification based on the kind of power source:

According to whether the system accepts single-phase (2-wire) power, the load or AC equipment in the power system can be classified as single-phase (2-wire) or three-phase (3-wire or 4-wire). or three-phase (3-wire) power supply. Or 4 cables). Various inverters are designed to eliminate PQ interference in the system. Voltage-related PQ faults in single-phase and three-phase networks have very similar characteristics. In addition, voltage asymmetry compensation is also required in order to deal fairly with the improved PQ 3-phase system. The main problem of single-phase systems is the regulation of reactive power and harmonic currents. In a three-phase three-wire system, the predicted current imbalance due to reactive current and current harmonics must be considered. A neutral wire current compensation circuit is required in a three-phase four-wire system $(3 \mathrm{P} 4 \mathrm{~W})$.

The methodology of finding harmonics in three phase Grid Connected Inverters is significantly simpler compared to single phase GCIs. Also, the single phase GCI is recognized to be generally an imbalance source, which poses further issues to the utility in addressing the problem of the imbalance source. As a result, three phase GCI provides a number of benefits that make it suitable for a wide variety of applications. Single-stage and two-stage GCI systems are also available with three phase GCIs. The following are some of the advantages of adopting a three-phase system in high-power applications:

- It decreases inverter switch stress.

- Reactive component sizes and ratings have shrunk.

- As the frequency of output current increases, the size of the output filter is reduced.

- It ensures that losses are distributed evenly.

As a result, in this study, a three-phase single-stage grid-connected PV system and a three-phase dual-stage grid-connected PV system was investigated. Interfacing PV modules with the grid through an inverter entails a number of needs and standards, which will be described in the second half of this chapter.

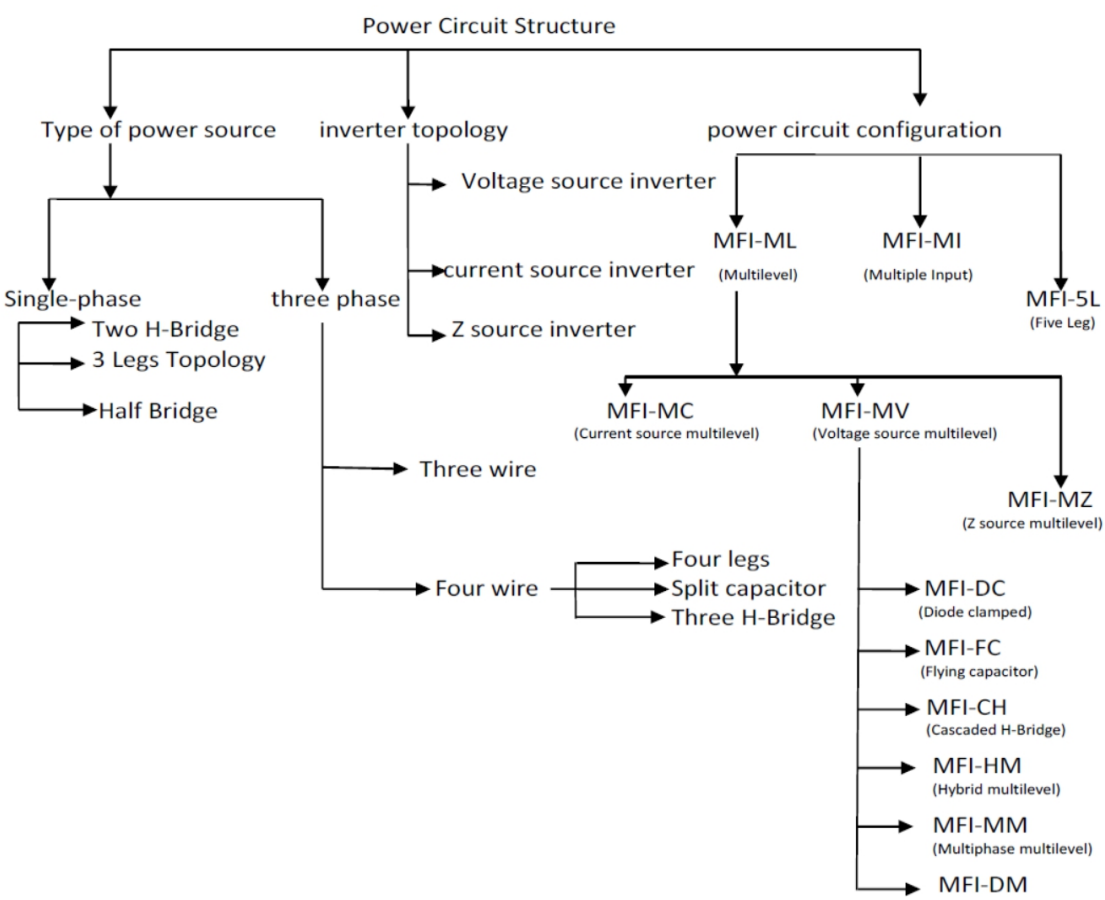


Figure 12: General classification of MFI Based on Circuit Power Structure.

\subsubsection{Inverter structure or topological classification:}

The grid-connected inverter keeps the DC link value at its chosen reference value. As a result, a current source inverter (CSI) is a type of inverter in which the DC side current has the same polarity as the AC side current, and the DC side voltage polarity determines the average power flow direction through the converter. A large inductor is frequently placed in series with the DC side of a CSI to keep the current flowing and make it more like a current source. The inverter can be generated using a pulse width modulated current source inverter (CSI), which uses a common inductor LDC to produce the DC bus. The construction of a CSI-based GCI system is shown in Fig. 13.

In comparison to the VSI, the CSI has not been widely employed for power system applications. This is owing to the CSI's requirement for bipolar electrical switches.

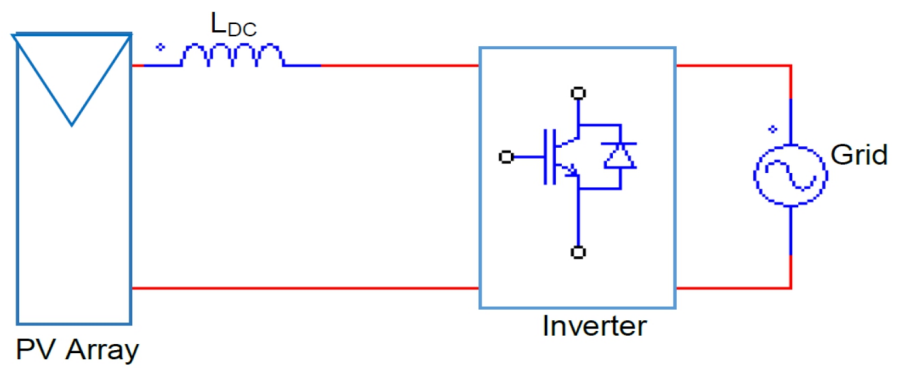

Figure 13: Topology of grid connected Current Source inverter system.

The second GCI topology is the voltage source inverter (VSI), which is the most commonly used GCI. This topology uses traditional CDC capacitors. In a voltage source inverter (VSI), the DC supply voltage maintains the same polarity, and the polarity of the DC supply current determines the direction of the average power flow from the converter. The VSI DC power supply is usually connected in parallel with a slightly larger capacitor that provides the voltage source; VSI is different from CSI in that it requires a reverse current switch or switch unit. The switching unit can be bought on the market as blocking line IGBT or IGCT. Before IGBT and IGCT were widely used, each switch in VSI was realized by connecting a GTO to a diode in anti-parallel.

In both standalone and grid-connected modes, VSI are used to convert energy from a DC source to an AC output. The single-line construction of a VSI-based GCI is shown in Fig. 14. In most GCIs, the VSI-based topology is adopted. In the VSI architecture, a blocking diode is not required. VSI is less expensive, lighter in weight, and allows for greater control and flexibility than the CSI topology.

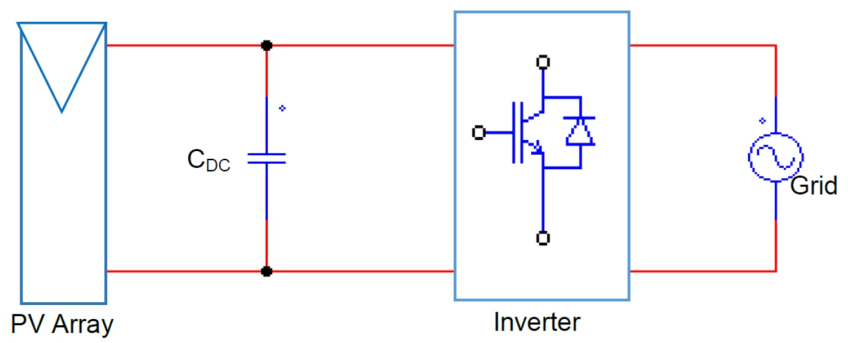

Figure 14: Topology of grid connected Voltage Source inverter system. 


\section{Inverter Configuration Classification}

Inverter topologies may be classified into three groups based on the number of power stages in the system:

- Single-stage inverters are inverters that have only one step of operation.

- Inverters with two stages

- Inverters with multiple stages

In a single-stage inverter, the maximum power point tracking current control loops and voltage control loops are all implemented in one stage, as shown in Fig. 15. (a). Maximum power point tracking is done by a DC to DC converter situated between the PV panels and the inverter in a dual-stage inverter, whereas control loops are handled by the inverter, as illustrated in Fig. 15. (b). Finally, each string is connected to a DC to DC converter for maximum power point tracking control; however, the control loops for a multi-stage inverter are accomplished by a single control inverter, as illustrated in figure15 (c).

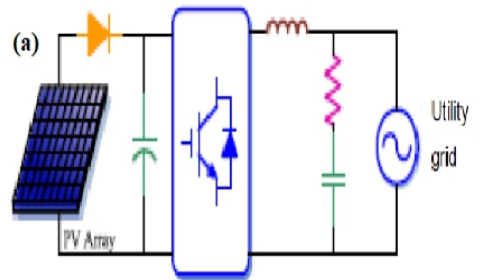

(b)

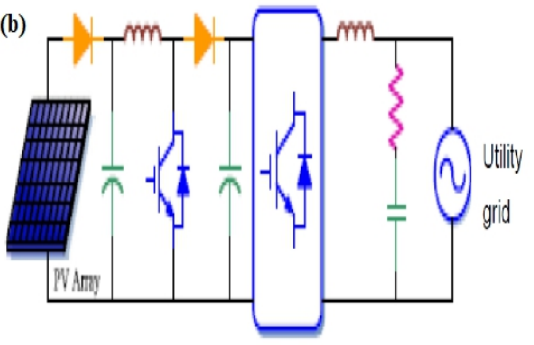

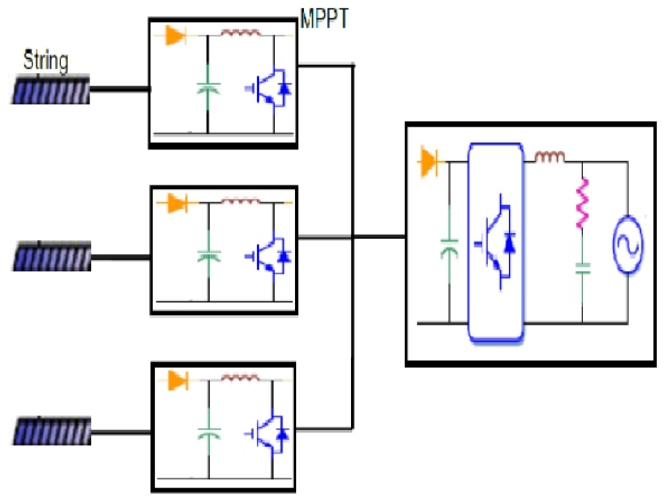

(c)

Figure 15: Different Inverter Configuration Classification

\subsection{Boost Converter}

A boost converter increases the DC voltage value at the input and supplies it at the output. Because the voltage from the PV panels is far too low for grid demand, a boost converter is necessary to convert the input voltage to the desired output voltage. An inductor, a diode, and a high frequency switch are the primary components of a boost converter. The control technique is based on changing the duty cycle of the switch, which results in a voltage change. The inductance value is calculated such that the converter runs in continuous conduction mode, which means that the inductor current IL never goes to zero. Capacitance is used to decrease output voltage ripple. 


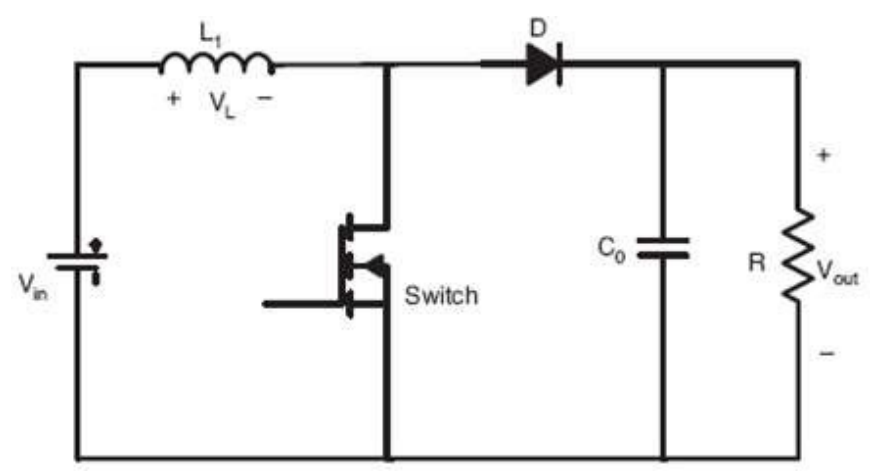

Fig 16: Boost Converter

Thus, inductor $\mathrm{L} \&$ capacitor $\mathrm{C}$ is given by :-

$$
\begin{aligned}
& \mathrm{V}_{\mathrm{O}}=\mathrm{V}_{\text {in }} /(1-\mathrm{D}) \\
& \mathrm{Lmin}=\left[(1-\mathrm{D})^{2 * \mathrm{D}} * \mathrm{R}\right] /[2 * \mathrm{f}] \\
& \mathrm{Cmin}=\mathrm{D} /(\mathrm{R} * \mathrm{f} * \mathrm{Vr})
\end{aligned}
$$

Where, $\mathrm{L}_{\min }=$ minimum inductance

$\mathrm{C}_{\min }=$ minimum capacitance

$\mathrm{D}=$ duty ratio

$\mathrm{R}=$ output resistance

$\mathrm{f}=$ switching frequency

$\mathrm{V}_{\mathrm{r}}=$ output ripple voltage $=\left(\Delta \mathrm{V}_{\text {out }} / \mathrm{V}_{\text {out }}\right)$

Because the voltage from the PV Panel is far too low for the framework's requirements, a lift converter is necessary to transform the information voltage to a suitable yield voltage. An inductor, a diode, and a high repetition switch are the main components of a lift converter. The control technique is used to regulate the switch's obligation pattern, which causes the voltage to vary. The inductance value is chosen so that the converter operates in continuous conduction mode, with the inductor current IL flowing continuously and never falling to zero. Swell yield capacitance is used to reduce yield voltage. Because the PV panel's output is extremely low, its voltage must be increased in order to connect it with the lattice. The PV module's yield is a DC voltage with a very low range.

As a result, a raise converter is necessary to increase the voltage to a higher level without the use of a transformer. An inductor, a diode, and a high repeat switch are the three most important components of an assist converter. These elegantly provide vitality to the store at a voltage that is unmistakably higher than the data voltage degree. To keep the stack voltage consistent, one capacitor is connected to the store end.

\subsubsection{Methods of Operation}

In an aid converter, there are two methods for activity. These take into account the switch's closing and opening. The switch is closed in the primary mode, which is known as the activity charging approach. The switch is open in the next mode, which is known as the activity discharging strategy. Figure 19 shows the 
circuit diagram of an assist converter.

\section{Mode of Charging}

The switch is turned, and the source charges the inductor via the switch. The charging current is exponential in nature, and it is assumed to be straightly fluctuating for simplicity. The excitement of the load is matched by the discharge of the capacitor, which reduces the flow of current from the source to the load as much as possible.

\section{Mode of Discharging}

The switch is open in the activity discharging method, and the diode is forward uneven. The inductor is now discharged, and the source, coupled with the capacitor, charges the capacitor and meets the storage demands. The pile's present assortment is almost nothing, and everything else is normal and reliable during the action.

\subsection{GRID}

The fig 17 shows the grid design that has been used for the simulation of this project in MATLAB software.

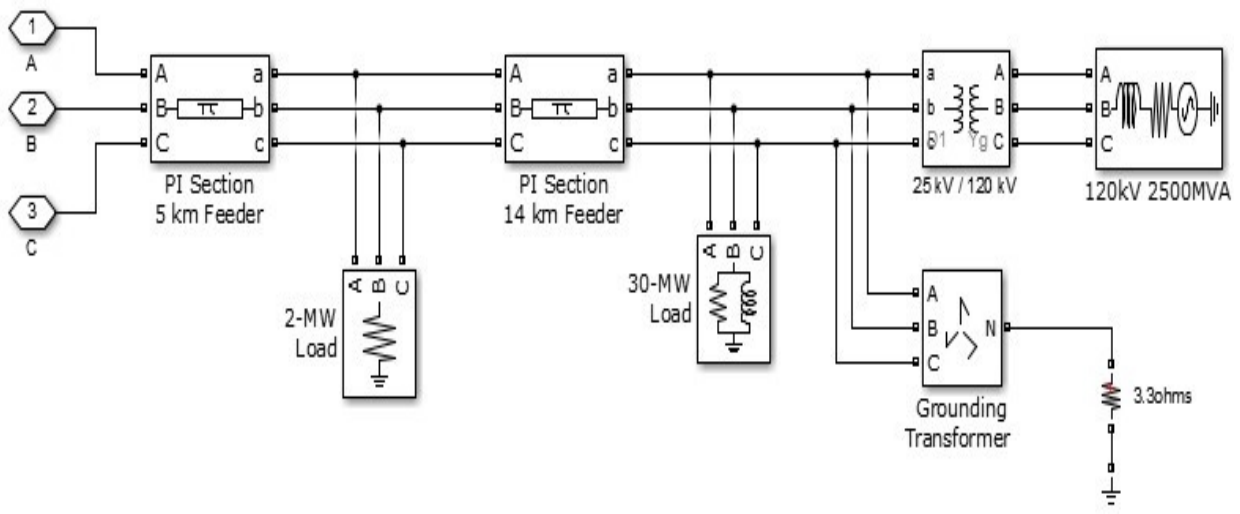

Fig 17: Grid Design

\section{Maximum Power Point Tracking}

A sun-based cell membrane efficiency is poor. Schedules must be developed in order to properly coordinate the source and burden with the ultimate goal of increasing proficiency. The Greatest Power Point Tracking is one such approach (MPPT). This approach is used to extract the most insane amount of electricity feasible from a fluctuating supply. The I-V twist in solar systems is non-direct, making it difficult to regulate a specific load. This is completed by comparing the obligation cycle of an aid converter with an MPPT computation.

MPPT, as an electronic system, is critical in allowing PV modules to produce the greatest amount of electricity they are capable of. It is not a mechanical tracking system that physically moves the modules to steer them closer to the sun. Because MPPT is an entirely electronic system, it changes the working point of the modules as a result, allowing them to supply the maximum amount of available power. PV system outputs are influenced by irradiance, temperature, and load factors. MPPT is unable to precisely supply the output voltage. To optimise the PV array output voltage, MPPT is necessary to 
be implemented in the PV system.

\subsection{Different Configuration of PV System}

The PV systems can be classified into two types, i.e., stand-alone and grid-connected PV system. There are numerous PV system configurations in the literature to improve the efficiency and performance of the PV system. The general PV system configurations of stand-alone PV system with DC and AC load and grid connected system are shown in Fig.21. Stand-alone PV systems can provide power supply to the load either from the PV source or battery or both, depending on the load requirement and available PV power. Grid connected PV system has the advantage of reduction of losses in the distribution line and the transformer. However, grid connected PV system is tedious in terms of grid synchronization. Thus, depending on the type of application and necessity, proper architecture has to be chosen for the design of the PV systems.

\subsection{Need of MPPT}

A single maximum point of power occurs in the power versus voltage curve of a PV module, i.e. a peak power corresponding to a voltage and current. The solar PV module has a poor efficiency of approximately $13 \%$. Because the module's efficiency is poor, it must be operated at its peak power point in order to deliver the most power to the load under variable irradiation and temperature circumstances. This increased power allows the PV module to be used more efficiently. The maximum power from the PV module is extracted by an MPPT and supplied to the load. This maximum power from the PV module was supplied to the load through an interface device DC/DC boost converter. The load impedance is changed and matched at the point of peak power with the source to transmit the greatest power by changing the duty cycle.

\subsubsection{Maximum Power Point Tracking}

A PV module can function as any of three different sources (i.e., current, voltage and power), depending on the location of the operating point on the I - V characteristics as shown in Fig. 22 (a). The operating point on the PV module's characteristic curve determines the efficiency of the PV system. The maximum power point, as depicted in Fig.18, is the point at which the PV module's available maximum power may be taken (b). By altering the duty cycle (D) of the converter, which is created by the MPPT algorithm, a DC-DC converter functions as an interface to operate at MPP. Maximum power point tracking (MPPT) is a critical function that should be included in every PV system, and these methods are based on the PV module's I - V and P - V properties. Direct duty cycle control, voltage reference control, or current reference control techniques can all be used to implement these algorithms. MPPT algorithms can be classified into mainly two categories; one is based on input parameters and the other is based on output parameters depending on the measured signals fed to the algorithm as described further.

4.3 Perturb and Observe Method Because of its simplicity, Perturb and Observe is the most often utilized MPPT approach. The length of $(\mathrm{dP}) / \mathrm{dV}$ is certain when the working voltage is increased, for example, when the voltage is increased the length of we receive more force. The operating voltage is lowered if 
$(\mathrm{dP}) / \mathrm{dV}$ is recognized as negative. If $(\mathrm{dP}) / \mathrm{dV}$ is near 0 within a predefined region, the voltage is held constant. When it comes to approaching the MPP, the time complex nature of this estimation is less, but it doesn't end there and continues to irritate. When the variety in sun-arranged illumination is considerable, this assessment isn't sensible. According to the $\mathrm{P} \& \mathrm{O}$ technique, it has a significant steady state error and a sluggish dynamic response. In reality, when a tiny change in value and a low sampling rate are used, the dynamic response is poor. Low increments are critical for reducing steady state error since the P\&O constantly makes the operating point fluctuate around the MPP, but never exactly at the MPP. The system will be closer to the array MPP if the increment is lower. The method will operate faster with a greater increment, but the steady state inaccuracy will increase. When the operating circumstances of the PV array changed, the tiny increments made the algorithm more precise and reliable. In case of huge increments the algorithm becomes confused since the response of the converter to large current or voltage variations will cause overshoot, oscillations and the settling time of the converter itself confuse the algorithm.

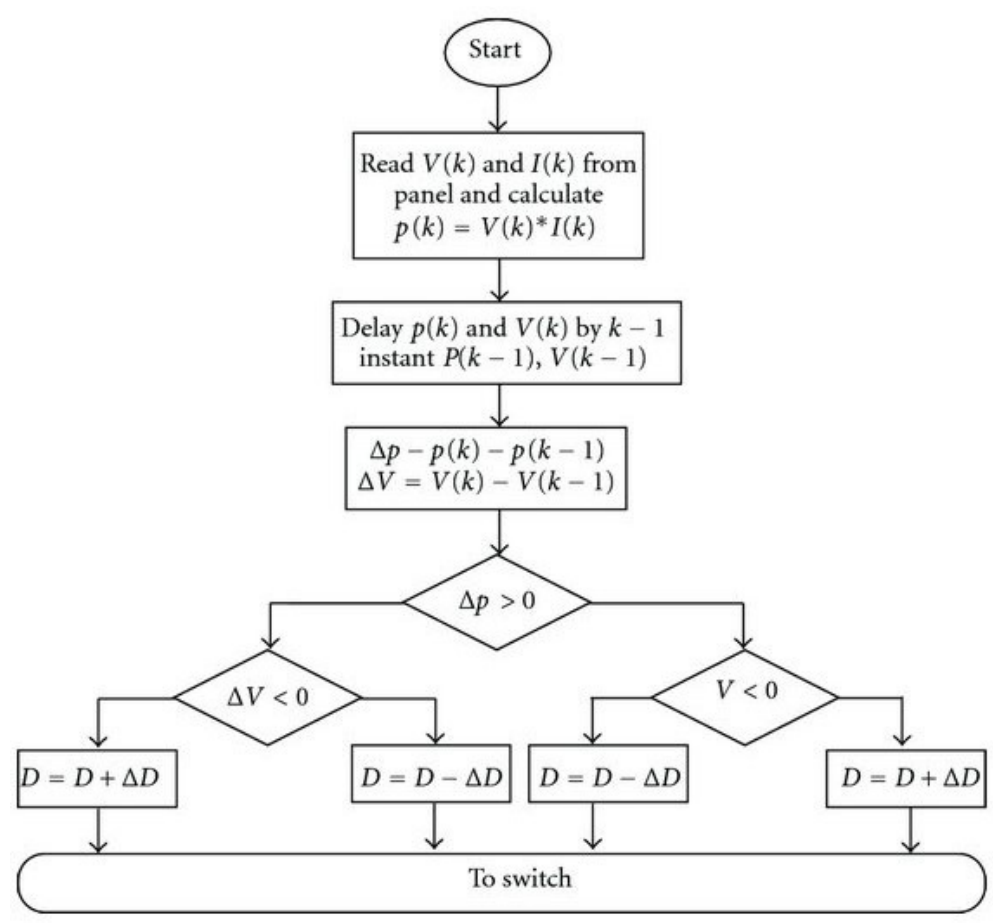

Fig 19: Flowchart of Perturb and Observe Algorithm

\subsection{Particle Swarm Optimization}

Particle swarm optimization (PSO) is inspired by various animals' social and cooperative behaviour in order to satisfy their needs in the search space. The algorithm is guided by personal experience (Pbest), global experience (Gbest), and the present movement of the particles to determine the particles' future locations in the search space. In addition, two components, $\mathrm{c} 1$ and $\mathrm{c} 2$, as well as two random values between $[0,1]$, were generated and it accelerate the experiences, whilst the current movement is compounded by an inertia factor w fluctuating between [wmin;wmax].

The initial population (swarm) of size $\mathrm{N}$ and dimension $\mathrm{D}$ is denoted as $\mathrm{X}=[\mathrm{X} 1, \mathrm{X} 2, \ldots, \mathrm{XN}] \mathrm{T}$, where $\mathrm{T}$ denotes the transpose operator. Each individual (particle) $\mathrm{Xi}(\mathrm{i}=1 ; 2 ; \ldots ; \mathrm{N})$ is given as $\mathrm{Xi}=[\mathrm{Xi} ; 1 ; \mathrm{Xi} ; 2 ;::: ; \mathrm{Xi} ; \mathrm{D}]$. Also, the initial velocity of the population is denoted as $\mathrm{V}=[\mathrm{V} 1, \mathrm{~V} 2, \ldots, \mathrm{VN}] \mathrm{T}$. 
Thus, the velocity of each particle $\mathrm{Xi}(\mathrm{i}=1 ; 2 ;:: ; \mathrm{N})$ is given as $\mathrm{Vi}=[\mathrm{Vi} ; 1 ; \mathrm{Vi} ; 2 ;:: . ; \mathrm{Vi} ; \mathrm{D}]$. The index I varies from 1 to $\mathrm{N}$ whereas the index $\mathrm{j}$ varies from 1 to $\mathrm{D}$.

The various stages of PSO are as follows:

1. Set the PSO parameters $\mathrm{w}_{\min }, \mathrm{w}_{\max }, \mathrm{c} 1$ and $\mathrm{c} 2$

2. Create a population of particles with locations $\mathrm{X}$ and velocities $\mathrm{V}$ at the start.

3. Set $\mathrm{k}=1$ as the number of iterations.

4. Calculate particle fitness $F_{i}^{k}=\mathrm{f}\left(X_{i}^{k}\right), \Delta \mathrm{i}$ and find the index of the best particle b

5. Select Pbest $_{i}^{k}=X_{i}^{k}, \Delta \mathrm{i}$ and Gbest $t_{i}^{k}=X_{b}^{k}$

6. $\mathrm{w}=\mathrm{w}_{\max }-\mathrm{k} \times\left(\mathrm{w}_{\max }-\mathrm{w}_{\min }\right) /$ Maxite

7. Update velocity and position of particles

$$
\begin{aligned}
& V_{i, j}^{k+1}=\mathrm{w}^{*} V_{i, j}^{k}+\mathrm{c}_{1} * \operatorname{rand}() * \text { Pbest }_{i, j}^{k}-X_{i, j}^{k}+\mathrm{c}_{2} * \operatorname{rand}() * \text { Gbest }_{j}^{k}-X_{i, j}^{k} ; \Delta \mathrm{j} \text { and } \Delta \mathrm{i} \\
& X_{i, j}^{k+1}=X_{i, j}^{k}+V_{i, j}^{k+1} ; \Delta \mathrm{j} \text { and } \Delta \mathrm{i}
\end{aligned}
$$

8. Evaluate fitness $F_{i}^{k+1}=\mathrm{f}\left(X_{i}^{k}\right), \Delta \mathrm{i}$ and find the index of the best particle b1

9. Update Pbest of population $\Delta \mathrm{i}$

$$
\text { If } F_{i}^{k+1}<F_{i}^{k} \text { then Pbest }{ }_{i}^{k+1}=X_{i}^{k+1} \text { else Pbest }{ }_{i}^{k+1}=\text { Pbest }_{i}^{k}
$$

10. Update Gbest of population

$$
\text { If } F_{b 1}^{k+1}<F_{b}^{k} \text { then Gbest }{ }^{k+1}=\text { Pbest }_{b 1}^{k+1} \text { and set } \mathrm{b}=\mathrm{b} 1 \text { else } \text { Gbest }^{k+1}=\text { Gbest }^{k}
$$

11. If $\mathrm{k}<$ Maxite then $\mathrm{k}=\mathrm{k}+1$ and goto step 6 else goto step 12

12. Print optimum solution as Gbest $^{k}$

The most commonly used parameters of PSO algorithm are considered as follows:

- Inertial weight: 0.9 to 0.4

- Acceleration factors (c1 and c2): 2 to 2.05

- Population size: 10 to 100

- Maximum iteration (Maxite): 500 to 10000

- Initial velocity: $10 \%$ of position 
A detailed flowchart of PSO considering the above steps is shown in Figure

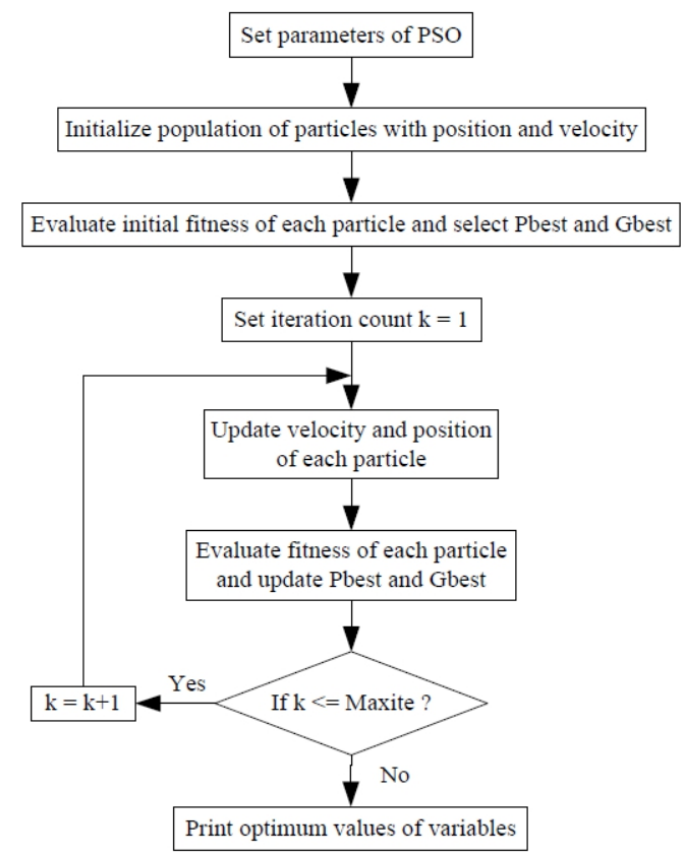

Fig 20: Flowchart of Particle Swarm Optimization

\section{SIMULATIONAND RESULTS}

This chapter gives an idea of various Simulink models and their associated results upon their perfect implementations. Here we will also see that there are also some measures taken in order to obtain the desired results by using the required filters.

\subsection{SIMULATION MODEL OF PV MODULE}

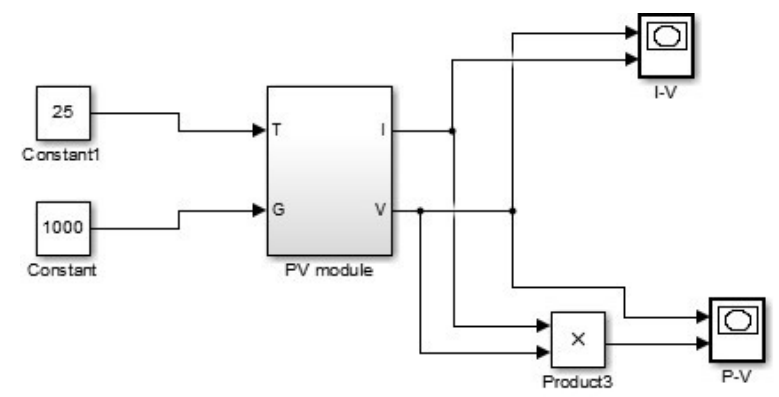

Fig 21: PV Model 


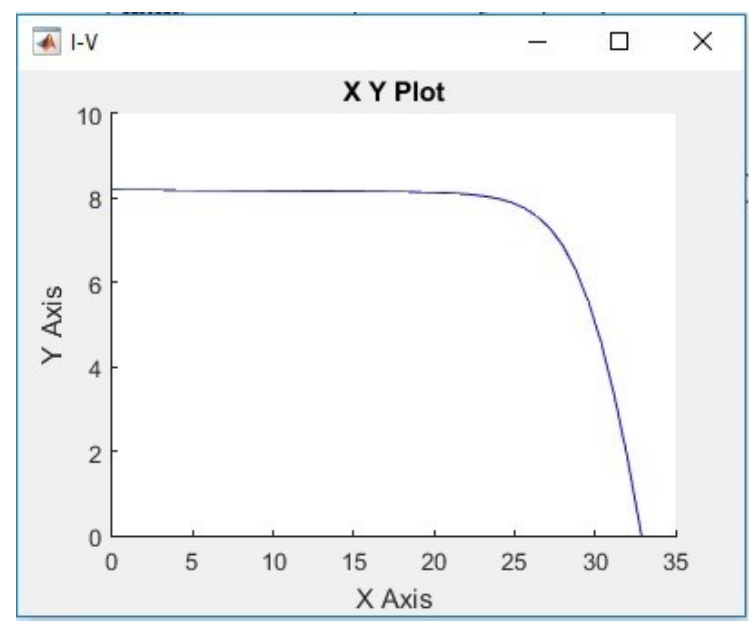

Fig 22: I-V plot

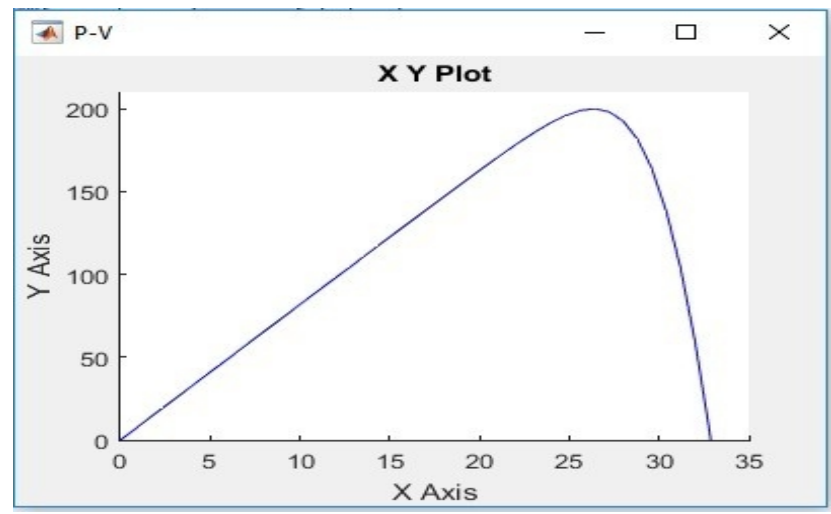

Fig 23: P-V plot

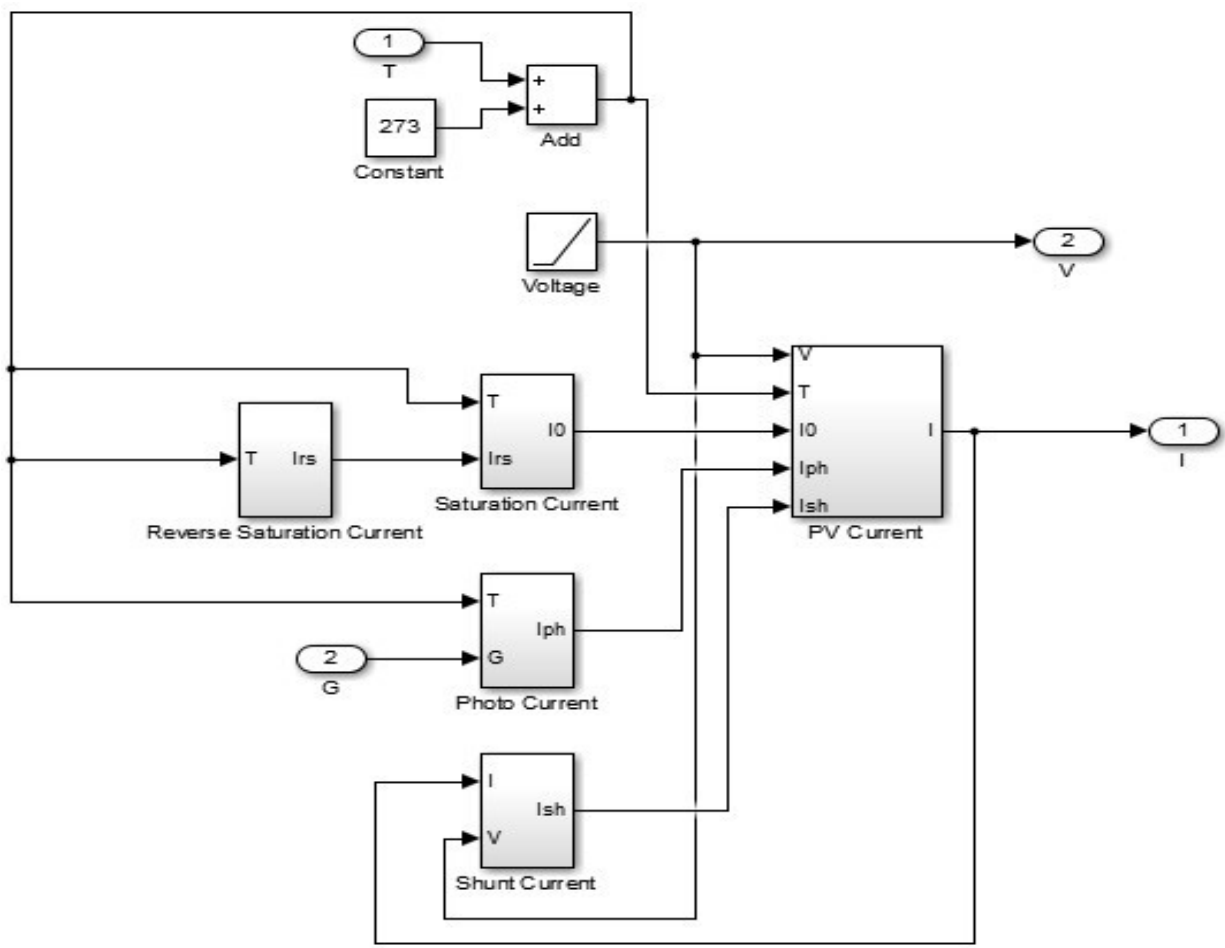


Fig 24: PV Module subset

\subsection{GRID}

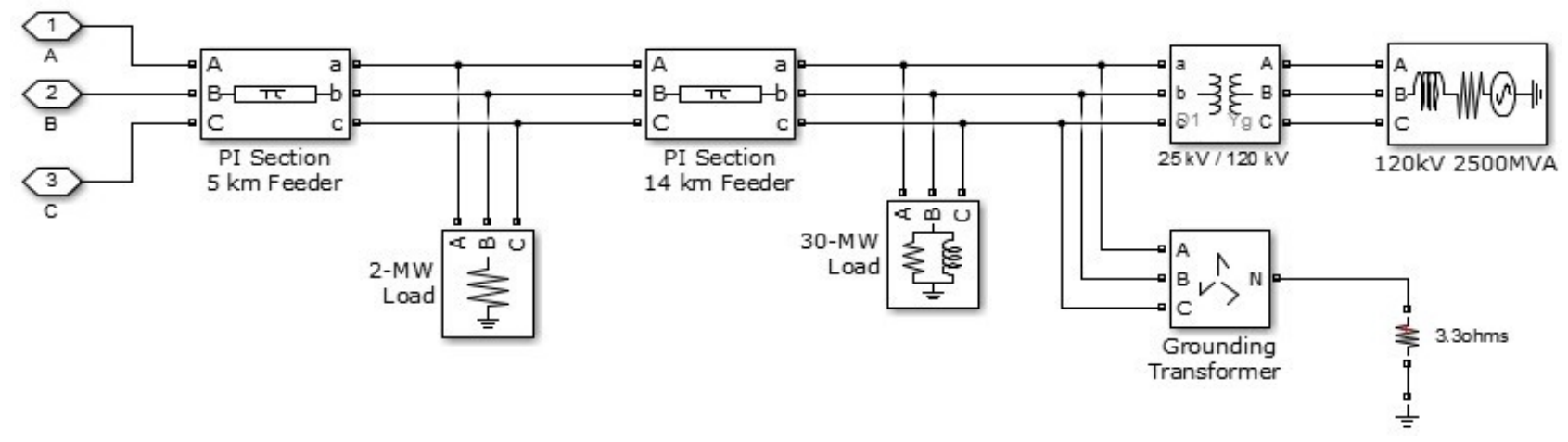

Fig 25: Grid Design

Simulink Model of Grid Connected Single Stage PV System

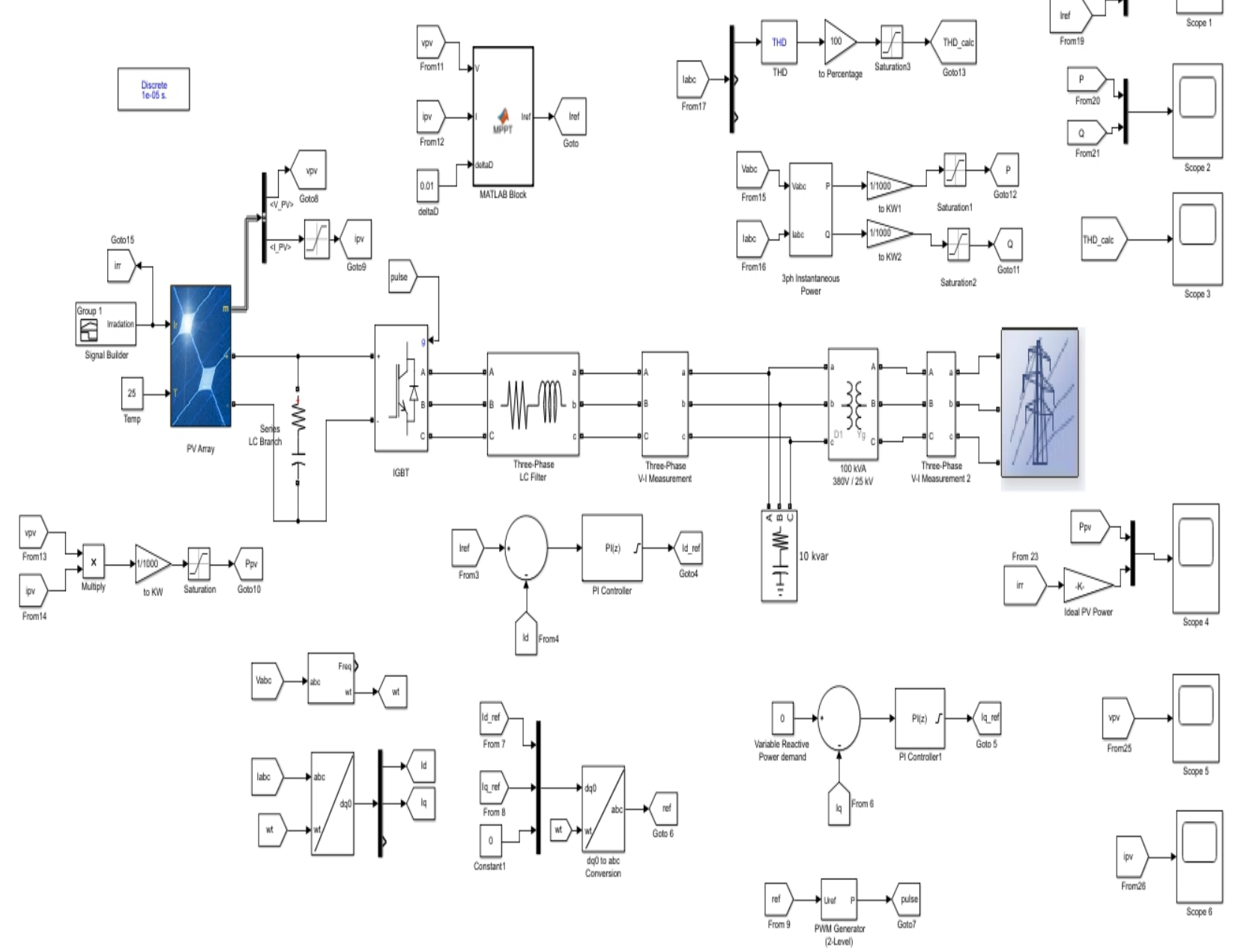

Fig 26: Single stage Grid Connected PV System

\subsection{Input Solar Irradiation}

The figure blow represent the graph of Irradiation that has been taken for the modelling of single stage solar pv system. This irradiation is designed by assuming the variation of solar irradiation during the day 
International Journal of Intelligent Communication, Computing and Networks

Open Access Journal (ISSN: 2582-7707)

https://doi.org/10.51735/ijiccn/001/32

time starting from zero and continuously rising to peak during the afternoon after that start reducing for the evening and finally reaches zero, and follow the same cycle everyday.

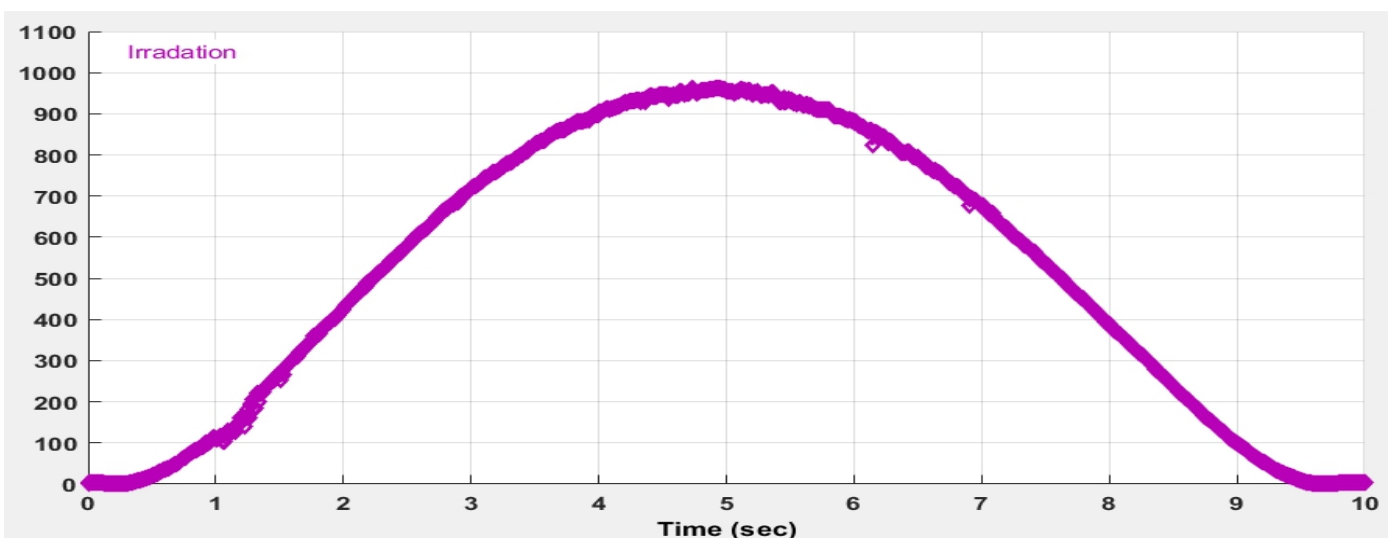

Fig 27: Solar Irradiation

\subsection{Result OF GRID CONNECTED SINGLE STAGE PV SYSTEM:}

\subsubsection{PV Voltage and PV Current}

In Single stage topology the PV is connected to inverter and PV voltage output works as input for inverter. In the PV result shown below this is the voltage of series connected photovoltaic modules from time $\mathrm{T}$ is equal to zero to time $\mathrm{T}$ is equals to 10 seconds. Due to the characteristic equation of solar PV cell the voltage variation is less with the variation in irradiation with time. As per the calculation we are getting voltage outputs from $800 \mathrm{v}$ to $850 \mathrm{v}$ with some variations with the good efficiency of whole system.

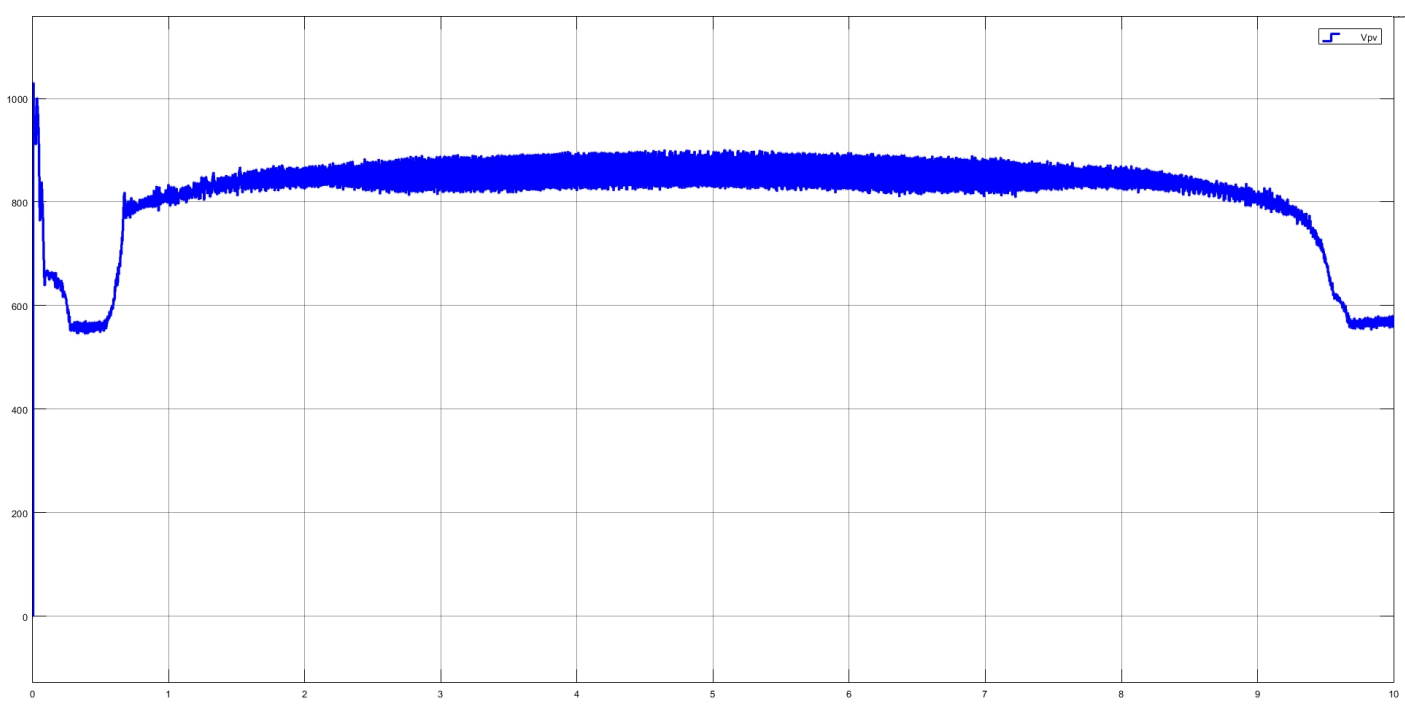

Fig 28: PV output voltage 


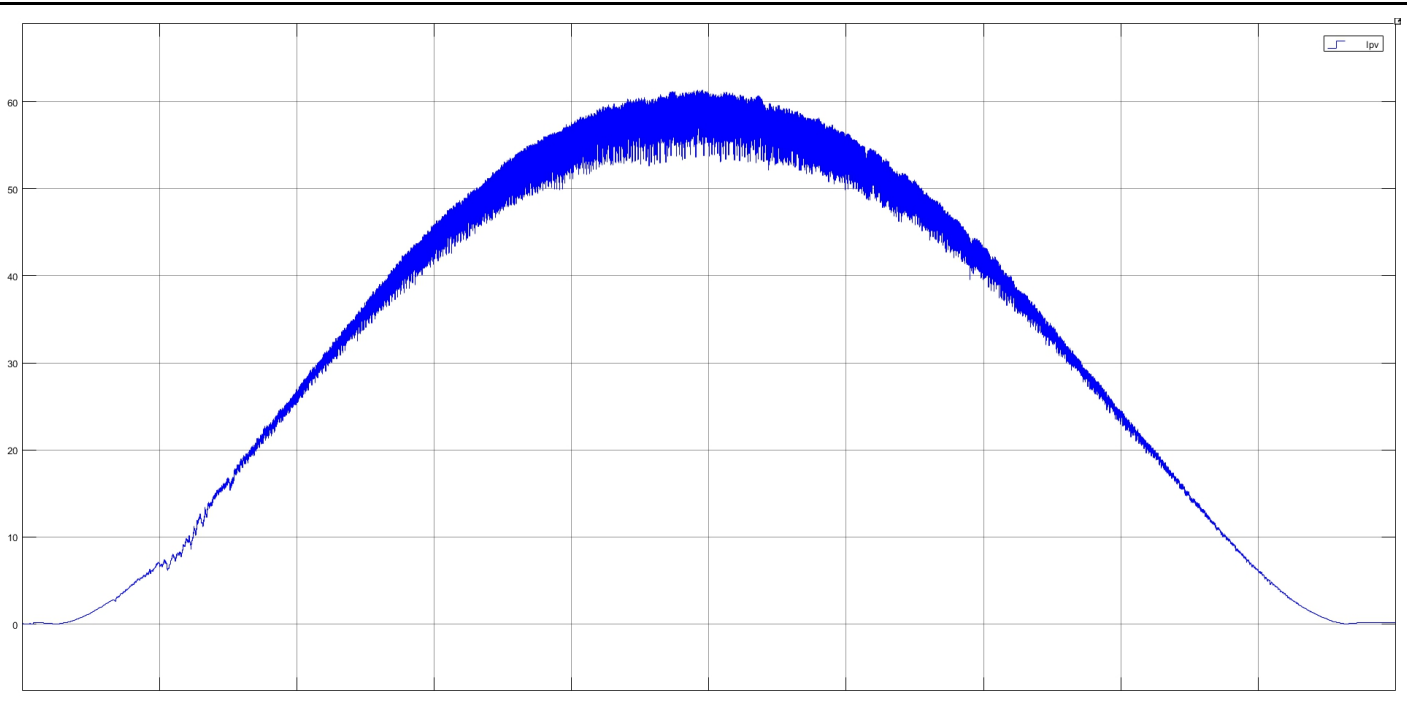

Fig 29: PV output voltage

It is clear from the characteristic equation of solar PV cell that the current variation is the major change with the variation in irradiation with time. Cureent folows the path of irradtion, so that if irradation goes down it means current will also go down and vice varsa. The current I maximum can be calculated by the total numbers of panels used in parrel to the current max at mppt.

\subsubsection{Output Current and Output Power}

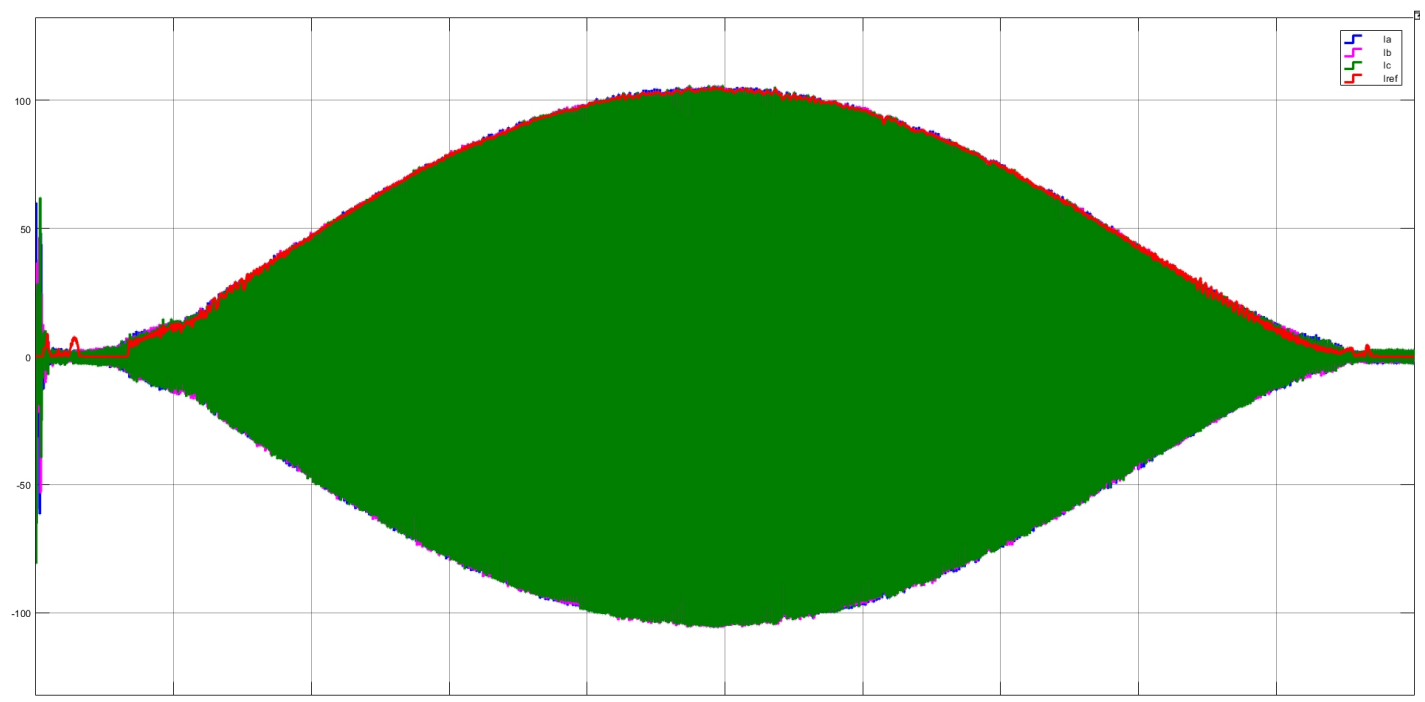

Fig 30: Output Current of Three phase grid connected system as per the Solar irradiation

The above figure 31 , represents the three-phase current as $\mathrm{I}_{\mathrm{a}}, \mathrm{I}_{\mathrm{b}}$, and $\mathrm{I}_{\mathrm{c}}$ from time $\mathrm{T}$ is equal to zero to time $\mathrm{T}$ is equals to 10 seconds. Here Red line represents the reference current generated from the SIMULINK model of this system and followed by all the three phase currents. In this result it can be easily observed that the current for the system does not exceed the limiting value and it can be set as per the requirement, so that the out graph will also change but it will surely not be going to exceed the liming vale that is set in the algorithm for the PV system. 


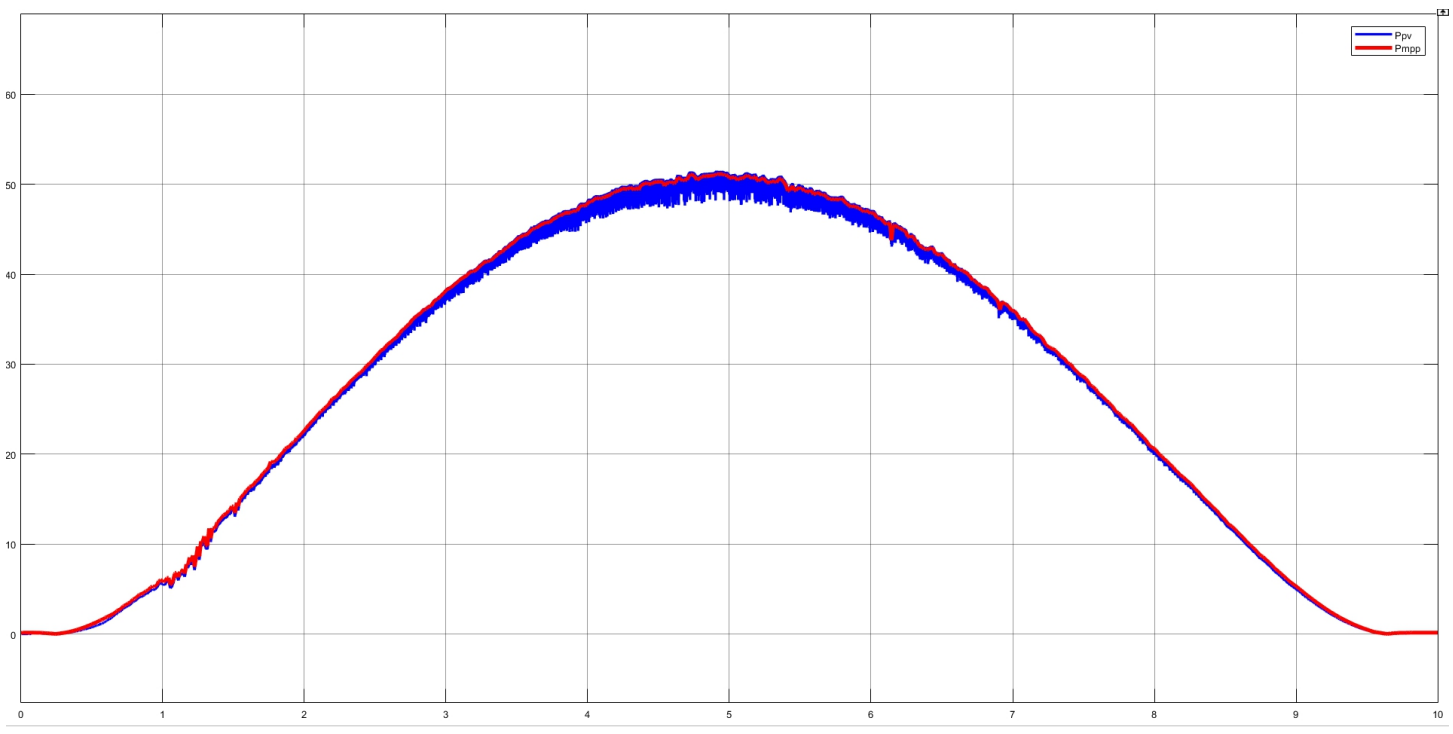

Fig 31: Output Power as per the Solar irradiation

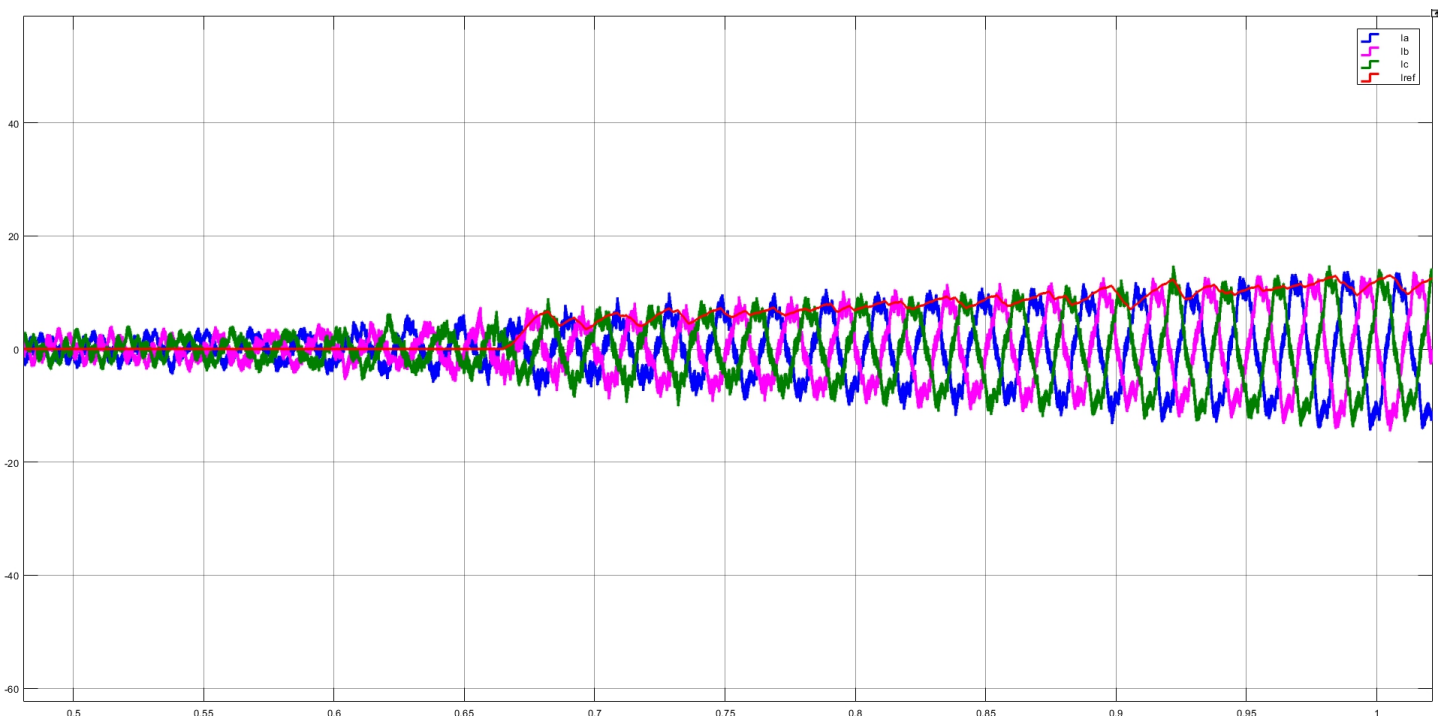

Fig 32: Output graph of Three-Phase current during starting period

In fig 31 it shows green but when we look little close, we can observe that it is the graph of three phase current. The above represents the three-phase current as $\mathrm{I}_{\mathrm{a}}, \mathrm{I}_{\mathrm{b}}$, and $\mathrm{I}_{\mathrm{c}}$ from time $\mathrm{T}$ is equal to zero to time $\mathrm{T}$ is equals to 1 seconds. While this period of time the reference current generated was zero for almost 0.67 seconds and along with this the three-phase current generated through PV system was almost zero. With the positive variation of solar irradiation along with time the generated current increases. 


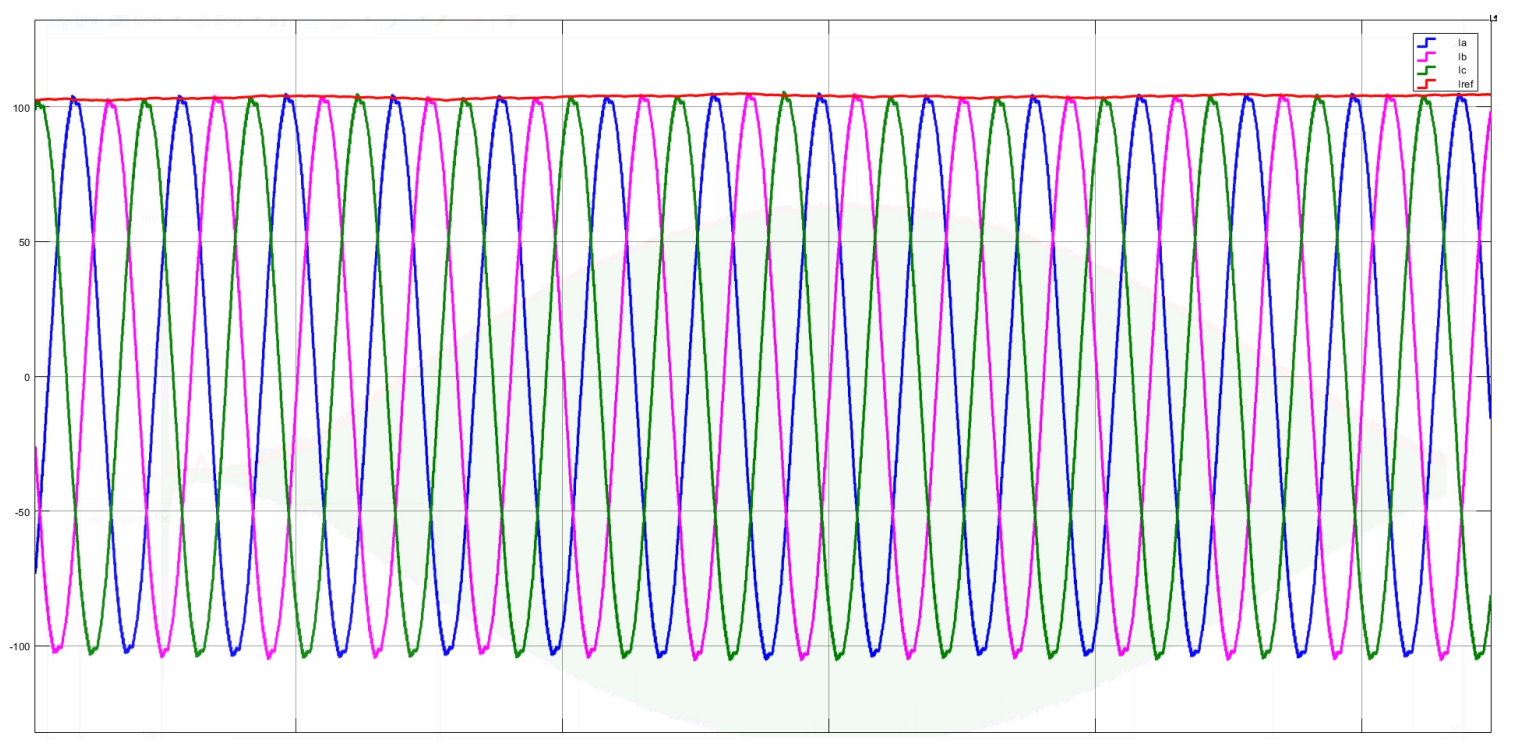

Fig 33: Output graph of Three-Phase current during Peak hours

The above represents the three-phase current as $\mathrm{I}_{\mathrm{a}}, \mathrm{I}_{\mathrm{b}}$, and $\mathrm{I}_{\mathrm{c}}$ during the peak hours of days when the solar irradiation is at its peak so the current also reached its peak value. While this period of time the reference current generated is at its peak value and along with this the three-phase current generated through PV system. With the positive variation of solar irradiation along with time the irradiation over time.

\subsection{Harmonics}

Reason for harmonics

- Nonlinear loads, or the great majority of power electronic equipment that use current in a non-sinusoidal way, are used.

- Due to fluctuations in the power sources.

- The currents' route (electrically) is excessively long, resulting in either high voltage distortion or telephone interference.

Need for harmonics removal

- Increase of line current within power system which can result in damage of electrical equipment.

- Overheating of transformer, motors, generators, cables, etc which can cause failure.

- Mis-operation of circuit breakers and other protection devices. Incorrect readings on meters. 


\subsection{SIMULINK MODELOF GRIDCONNECTED DUALSTAGE PV SYSTEMWITH P\&O}

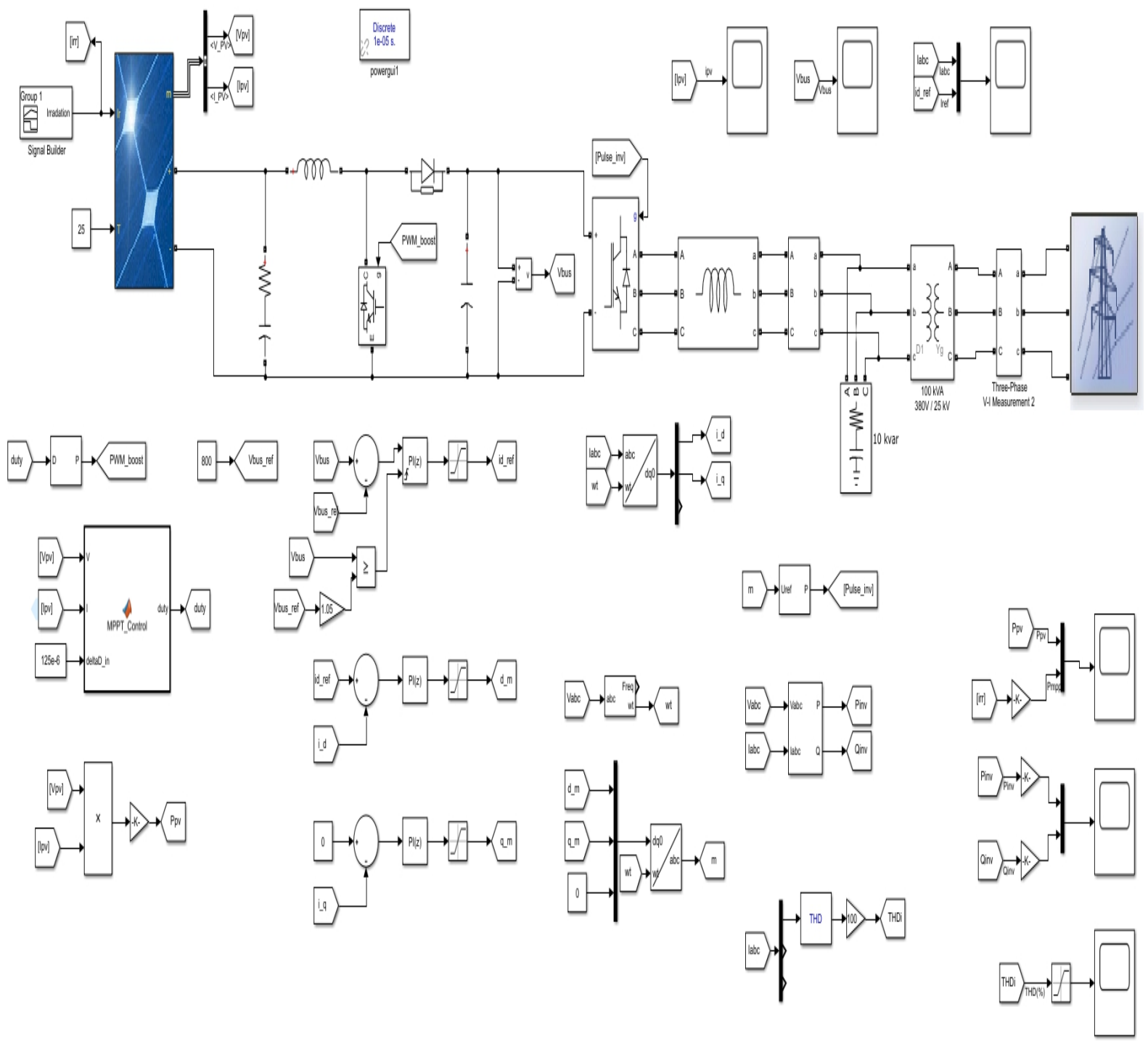

Fig 34: Dual stage Grid Connected PV System

\subsubsection{PV Results for Voltage and Current}

In Dual stage topology the PV is connected to a boost converter where boost converter step up the output voltage coming from PV and supply this boosted voltage to the inverter and booster voltage output works as input for inverter. In the result shown below this is the voltage of connected photovoltaic modules from time $\mathrm{T}$ is equal to zero to time $\mathrm{T}$ is equals to 10 seconds. As per the calculation we are getting voltage output about 800 volts with some variations with the good efficiency of whole system. 


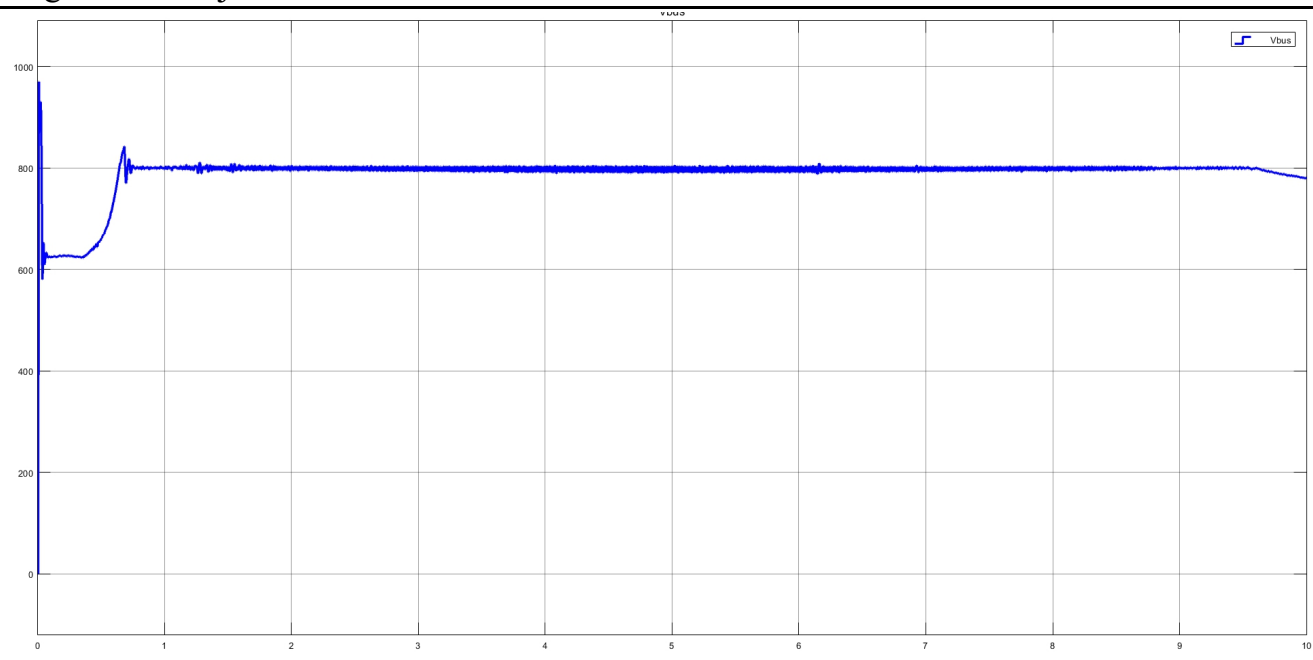

Fig 35: Output voltage of boost converter in PV System

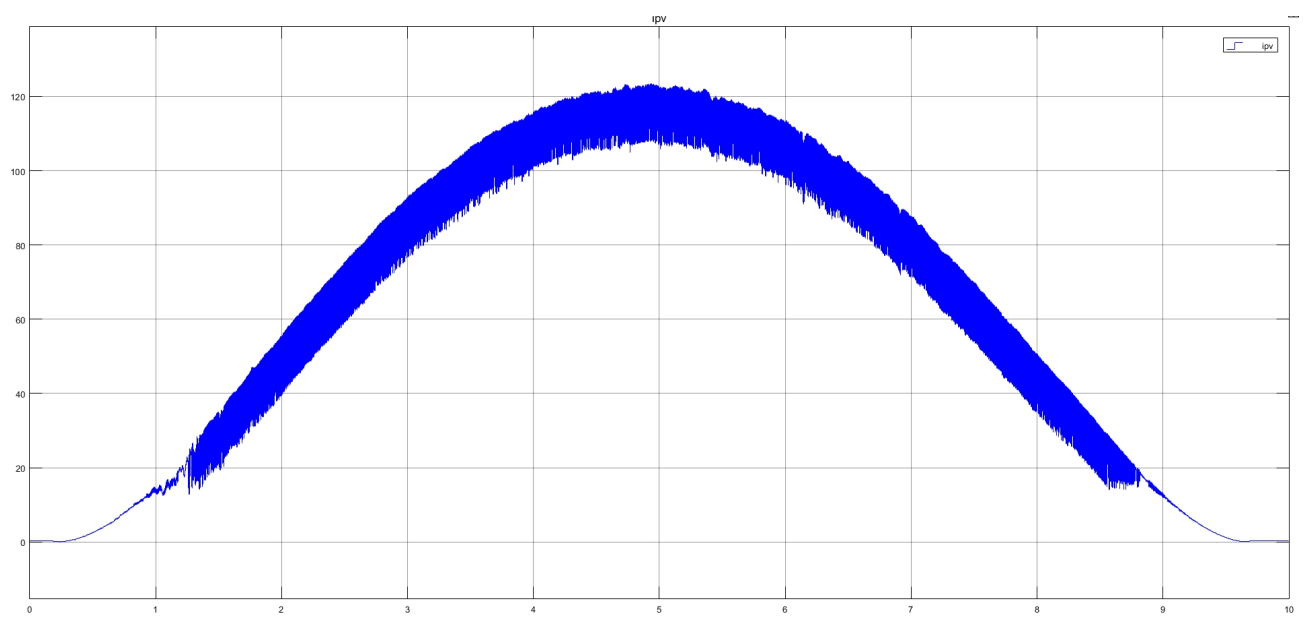

Fig 36: Output current of PV System

The figure 36 represents the PV current values. There are heavy deviation and this should be reduced so that we can supply this.

\subsubsection{Output Current and Output Power}

As per the all the $\mathrm{PV}$ system is designed for $50 \mathrm{KW}$ power ratings as further the comparison is possible. The below figure 37, represents the total three-phase power output in the system from time $\mathrm{T}$ is equal to zero to time $\mathrm{T}$ is equals to 10 seconds. Here Red line represents the ideal power output for the MPPT values for the solar module used in the system generated. In this result it can be easily observed that the power outputs for the system does not exceed the limiting values 


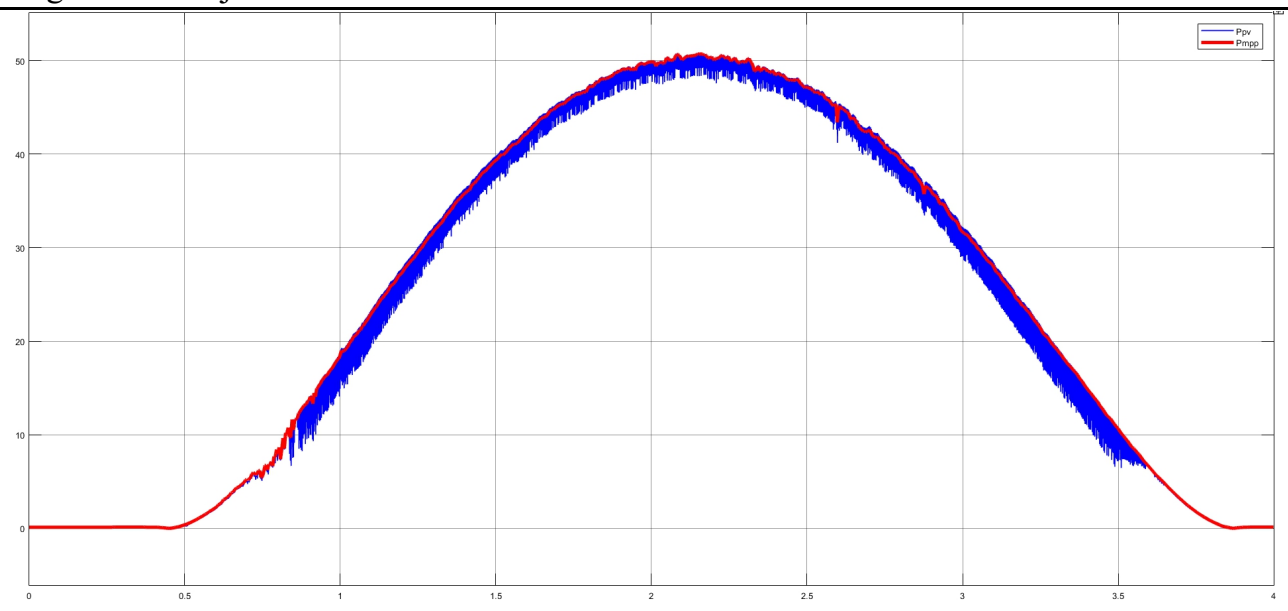

Fig 37: OutputPower in the Grid connectedPVSystem

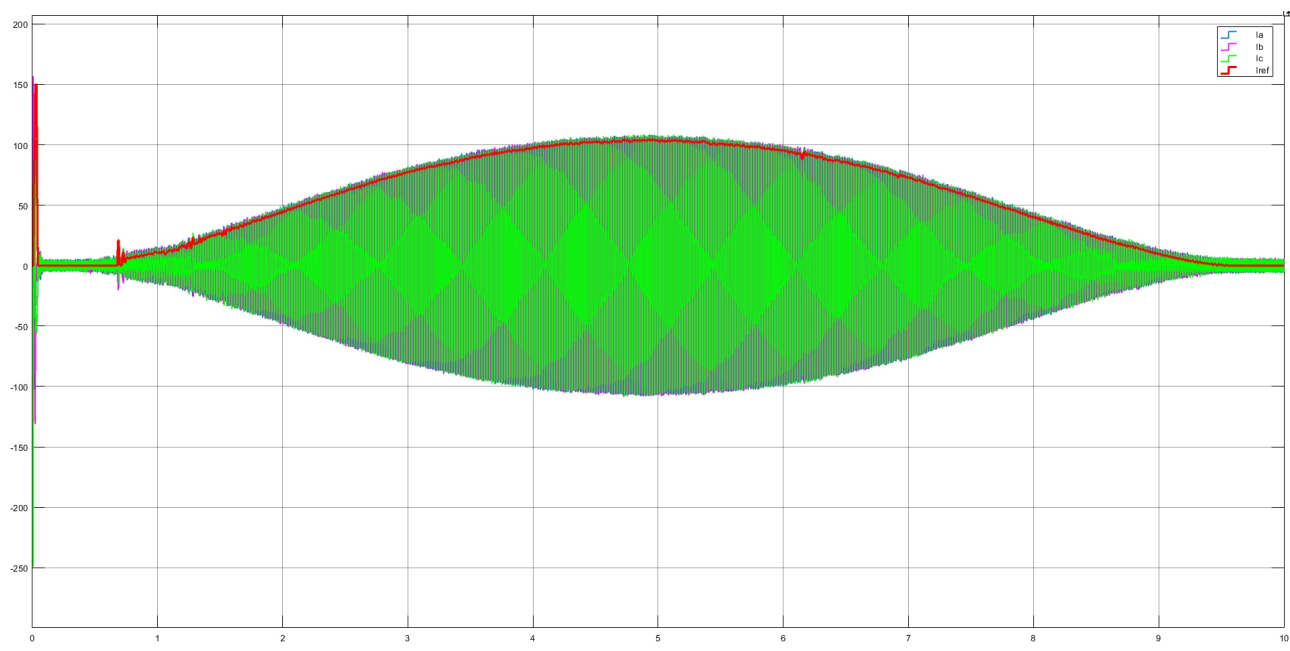

Figure 38: Output Current of Threephase grid connected system as per the Solar irradiation.

\subsection{SIMULINKMODEL OFGRIDCONNECTEDDUALSTAGE PVSYSTEMWITHPARTICALSWARM} OPTEMIZATION(PSO)

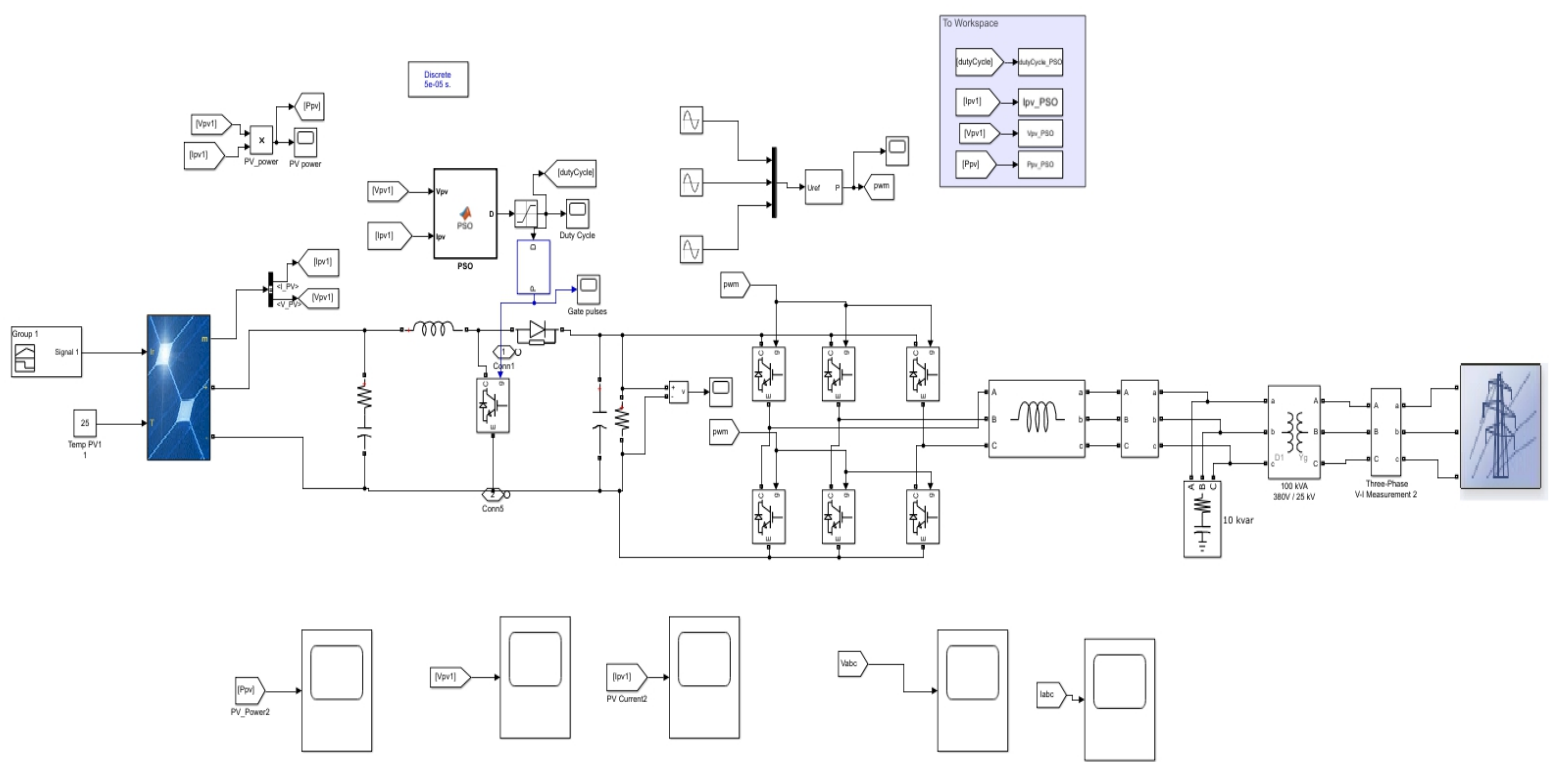

Fig 39: Dual stage Grid Connected PV System with PSO MPPT. 


\subsubsection{Results of PSO based PV System for Voltage, Current and Power}

In PSO based Dual stage topology the PV is connected to a boost converter where boost converter step up the output voltage coming from PV and supply this boosted voltage to the inverter and booster voltage output works as input for inverter. In the result shown below this is the voltage of connected photovoltaic modules from time $\mathrm{T}$ is equal to zero to time $\mathrm{T}$ is equals to 10 seconds. Where the fluctuation during the staring shows the charging and discharging of boost converter.

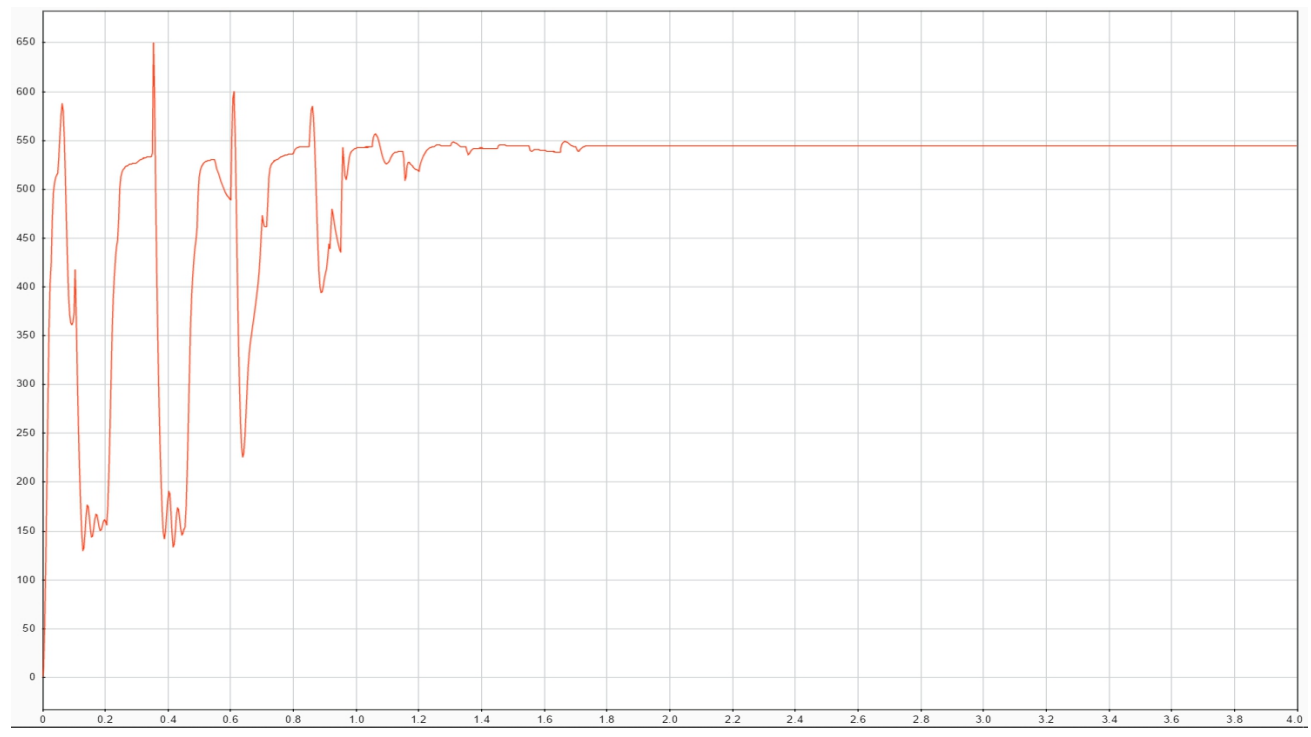

Fig 40: Output voltage of boost converter in PSO PV System

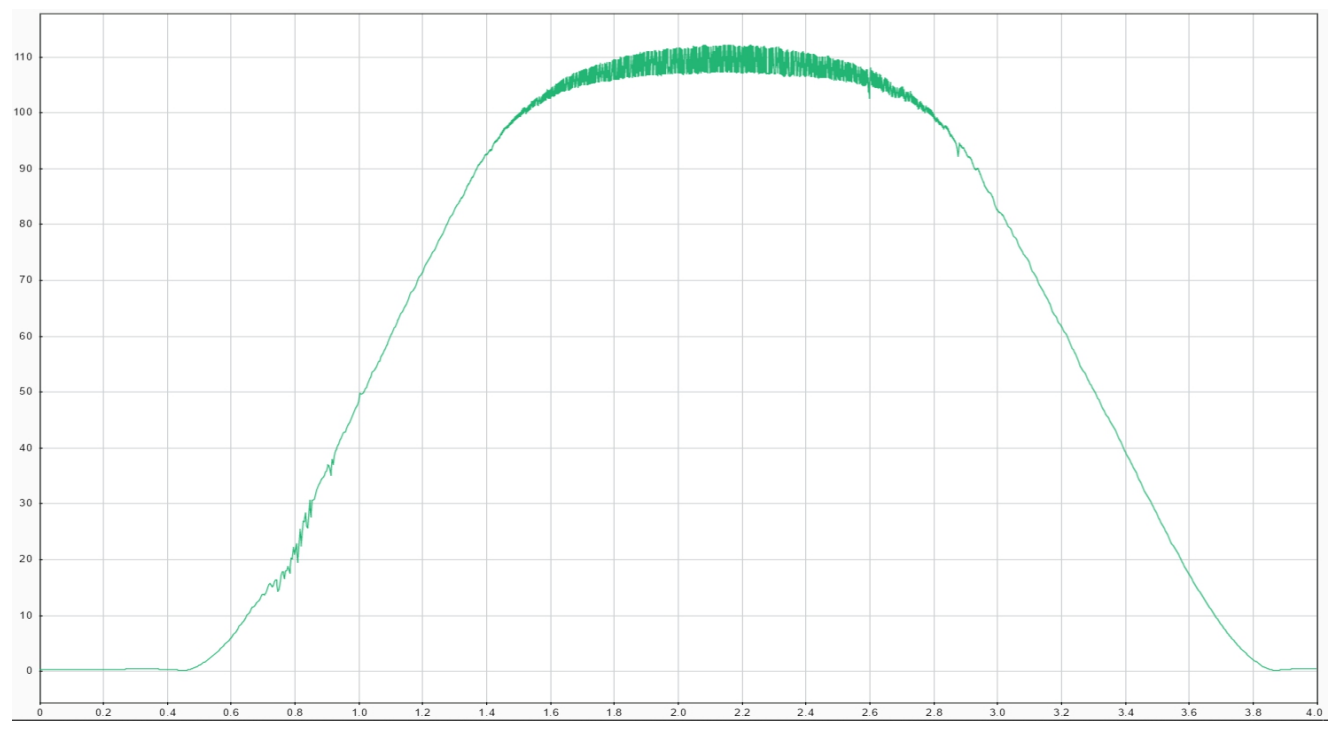

Fig 41: Output current of boost converter in PSO PV System

The figure 41 represents the PV current values for PSO based PV system. There is less deviation as compare to the $\mathrm{P} \& \mathrm{O}$ based PV system and this can be reduced further by changing in algorithm.

As per the all the PV system is designed for $50 \mathrm{KW}$ power ratings as further the comparison is possible. The below figure 50, represents the total three-phase power output in the system from time $\mathrm{T}$ is equal to zero to 
time $\mathrm{T}$ is equals to 10 seconds.

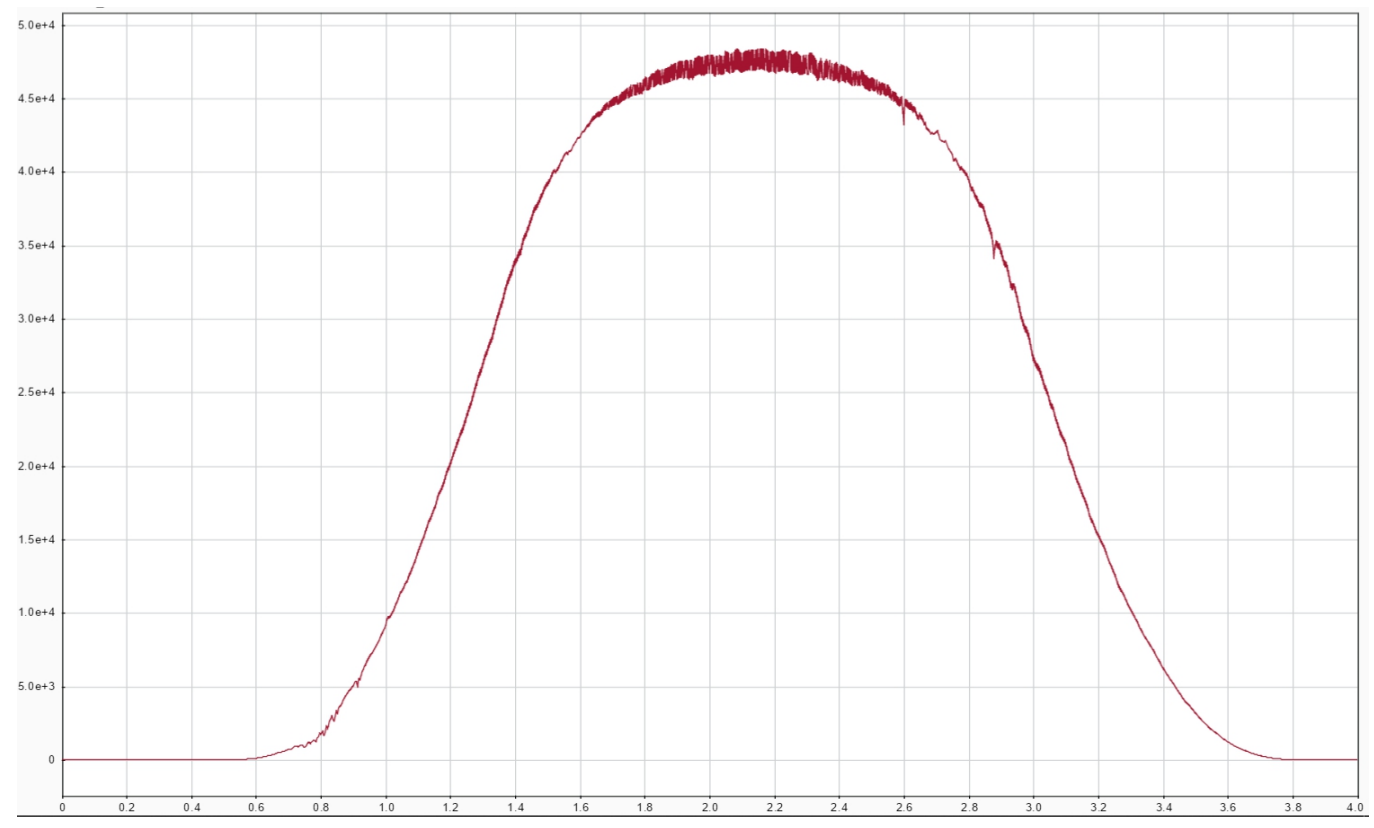

Fig 42: Output power curve for PSO based PV System

Here the power output values are slightly less than the P\&O based dual stage PV system. The particular reason behind that is reduction of current output in PSO based PV system, and this current reduction is dependent on the PSO algorithm used and if we improve this algorithm then we can get better current and power output results.

\section{COMPARITIVE STUDY OFSINGLE STAGEANDTWOSTAGE PVSYSTEM}

Single stage operation of a DC source that is PV cells, a DC-AC inverter, MPPT, controlling unit and load or grid. DC supplies from the solar cell is connected to the inverter that directly convert DC into AC further the system can be connected through the load or grid. The controlling unit plays important role here for MPPT tracking. Schematic representation of single stage PV cell operation is shown here.

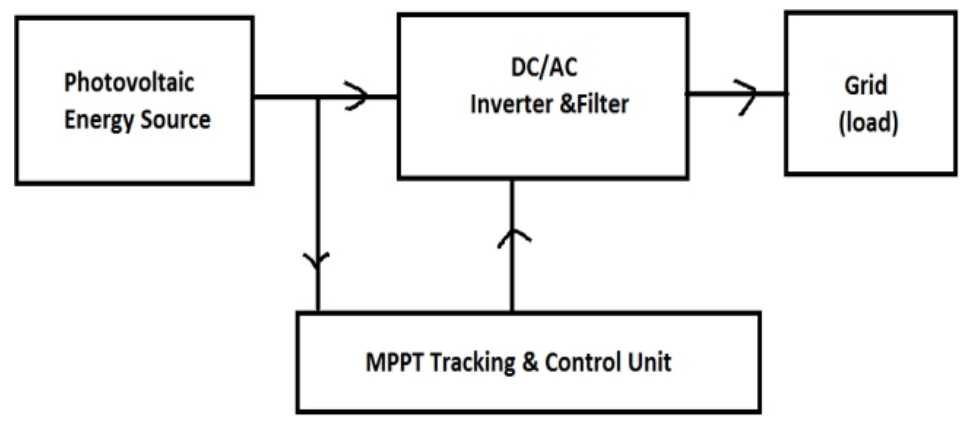

Figure 43: Single Stage Operation

One extra component is inserted throughout the two-stage process. PV cells, a DC-DC converter, a DC-AC inverter, a controlling device, and a load or grid operate in two stages. Using DC-DC converters, the DC output of PV cells is first boosted or stepped up, and then this step-up DC is reversed into AC according to load or grid demand using inverters. 
The output voltage of a PV array is usually inadequate to connect to the grid. Furthermore, the voltage source inverter (VSI) frequently has a voltage-down characteristic, resulting in a lower voltage produced by the "PV array + Inverter" design, necessitating the use of two stages. A voltage-up connector is included in this design. Schematic representation of two stage operation of PV cell is shown here.

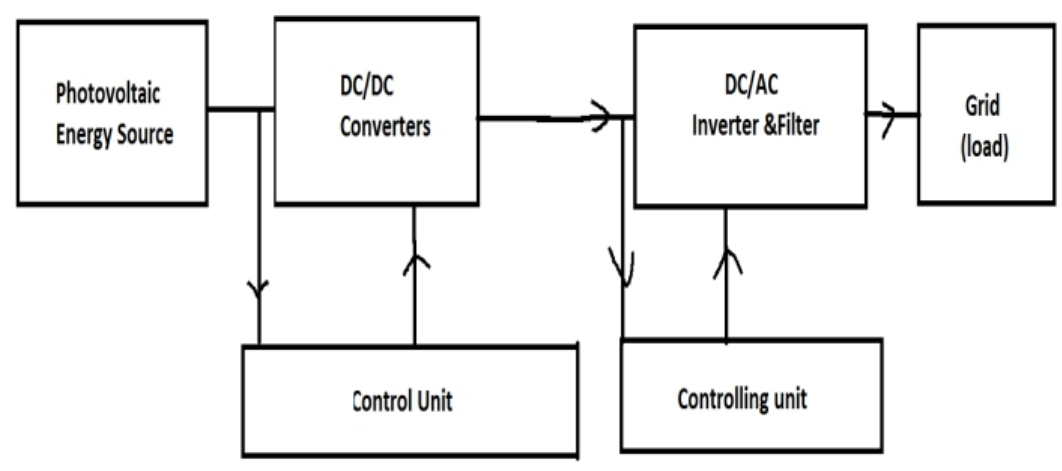

Figure 44: Two stage operation

The maximum power point tracking current control loops and voltage control loops are all implemented in one stage in a single-stage inverter, as shown in Figure 15a. In a dual-stage inverter, maximum power point tracking is performed by a DC to DC converter located between the PV panels and the inverter, as shown in Figure 15b, while control loops are handled by the inverter. Finally, each string is linked to a DC to DC converter, allowing for maximum power point tracking control, while the control loops of the multi-stage inverter are handled by a single control inverter, as shown in Figure 15c.

\section{In terms of Cost:}

For the same power output ratings the single stage operation requires more number of solar panels. As in this project all systems were designed for $50 \mathrm{kw}$ power but in single stage we set $21 * 17$ solar panels to get the satisfying level of power outputs but in dual stage we only needed $17 * 14$ panels reach our goal of 50 $\mathrm{kw}$ it is just because of additional second stage that is boost converter. This reduced the number of panel required and so the overall cost for the system. But on the other side, it is matter of fact that we need this boost converter system to reduce that much panels to achieve the goal so that means it is having some components that costs us. While researching and analyzing the system it is clear that the cost of boost converter will be so less as compared to the amount of extra PV panels those were used in single stage PV system.

\section{In terms of power loss:}

The two-stage architecture has advantages in controller design, but it also has disadvantages $[21,22]$. The power loss increases as the number of circuit stages increases, lowering total energy transfer efficiency; more stages also increase system complexity, reducing system reliability. The AC side of two stages has less non-characteristic and low order harmonics than the single stage, as demonstrated by the THD item, due to a more stable DC voltage control effect. The PV array output values are all around the MPP in four scenarios (losses are caused by filters dissipation and control oscillation). The MPPT accuracy of the two topologies appears to be fairly close [23].

There are two standard MPPT algorithms constructed, as well as some out loop controller design details. 
The results demonstrate that the created models and controllers are effective.

When the two topologies are compared, it is apparent that 1) the single stage topology is the more efficient.

2) A two-stage architecture provides better DC voltage stability and AC side voltage THD.

3) Accuracy of MPPT: both can meet accuracy requirements within an acceptable error range for controller oscillation and ac filter loss.

In a summary, the PV system models presented in this paper may be used in simulation studies for a certain sort of grid-connected PV producing event. Engineers can use the simulation findings.

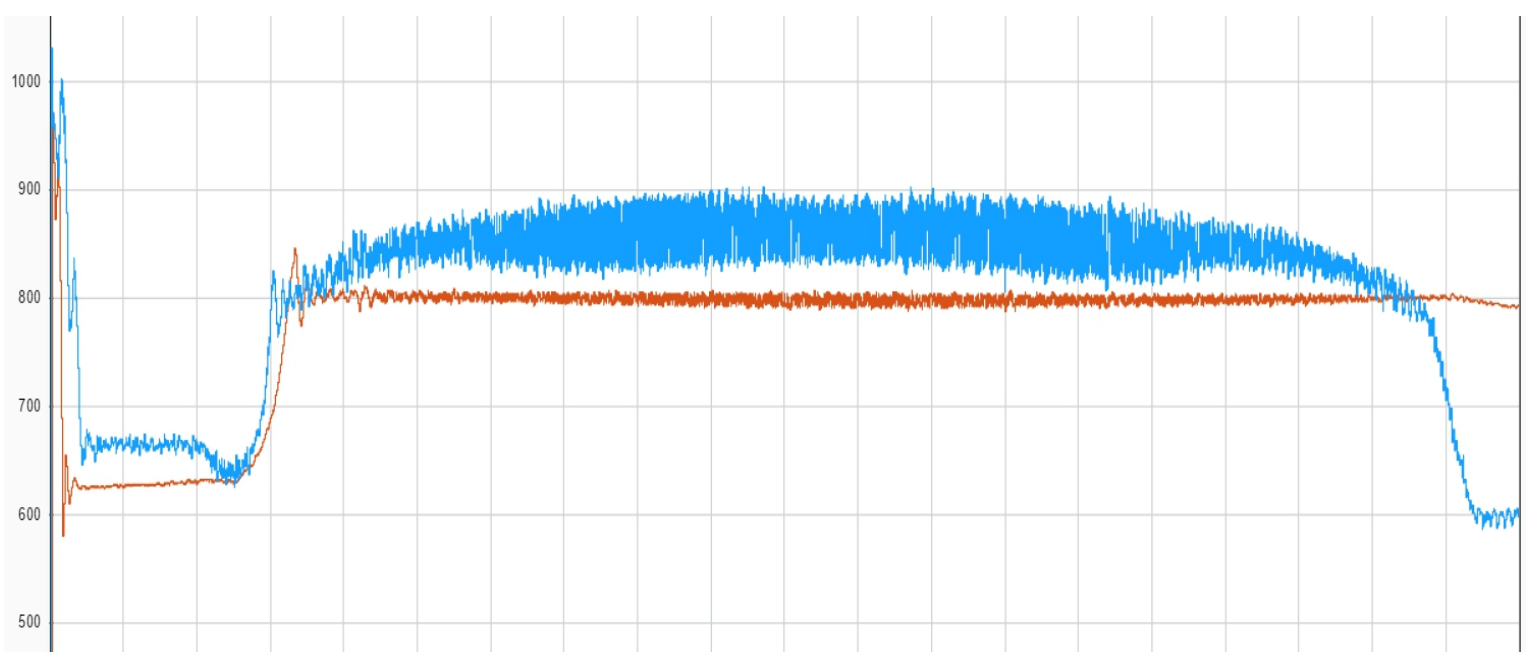

Fig 45: Single Stage and Dual Stage inverter input Voltage Graph

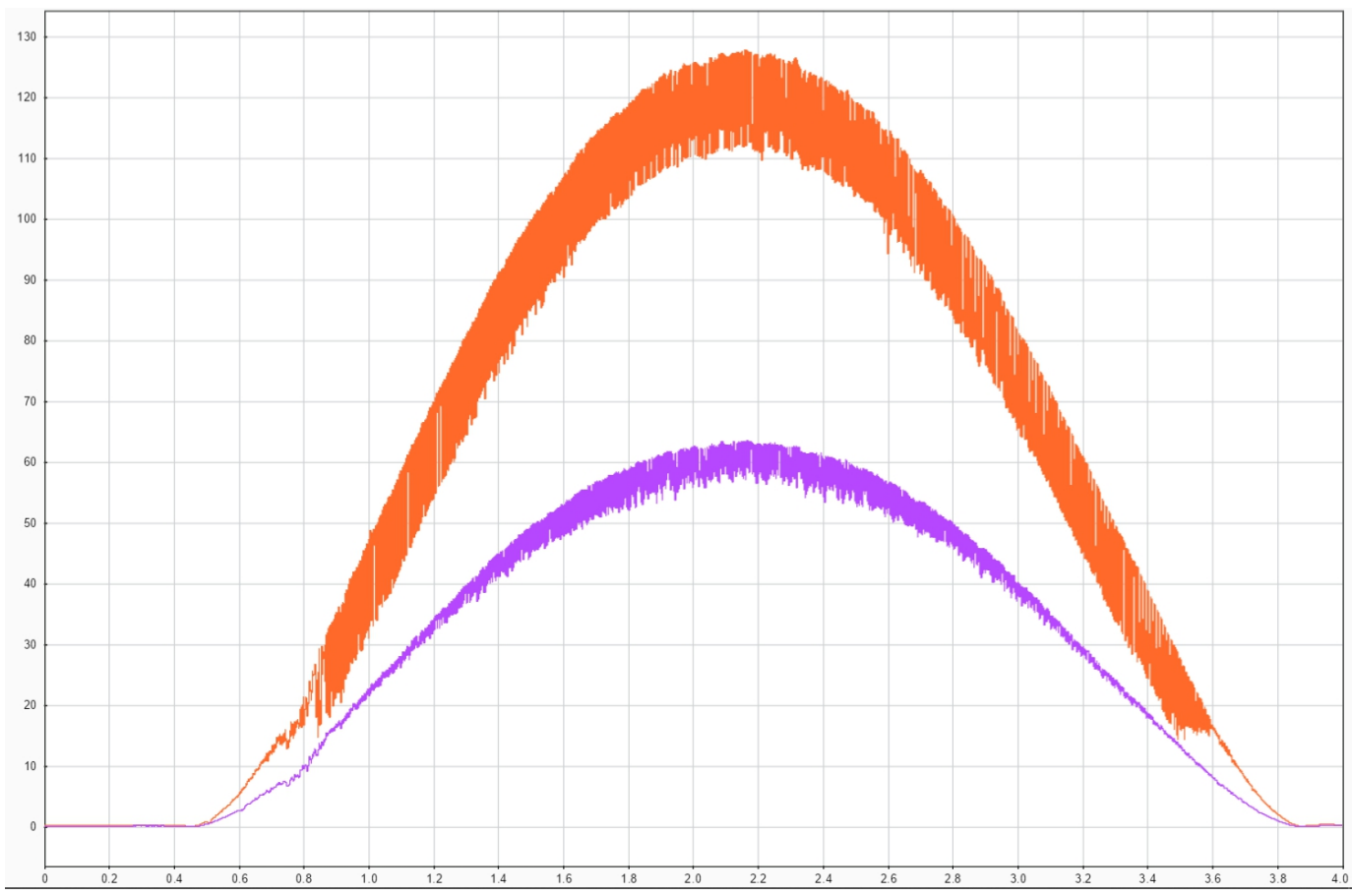

Fig 46: Single Stage and Dual Stage PV Current Graph

\subsection{Comparative Results of PSO and P\&O based PV System for Voltage}

The brown color represents the boost converter voltage for P\&O based PV system where we can see that 
the variation in voltage is continuously present and The violet color represents the boost converter voltage for PSO based PV system where we can see that the fluctuation during the stating period occurs due to the charging and discharging of the boost converter's capacitor after that the this fluctuation in voltage reduces and we obtain a constant value of voltage in result.

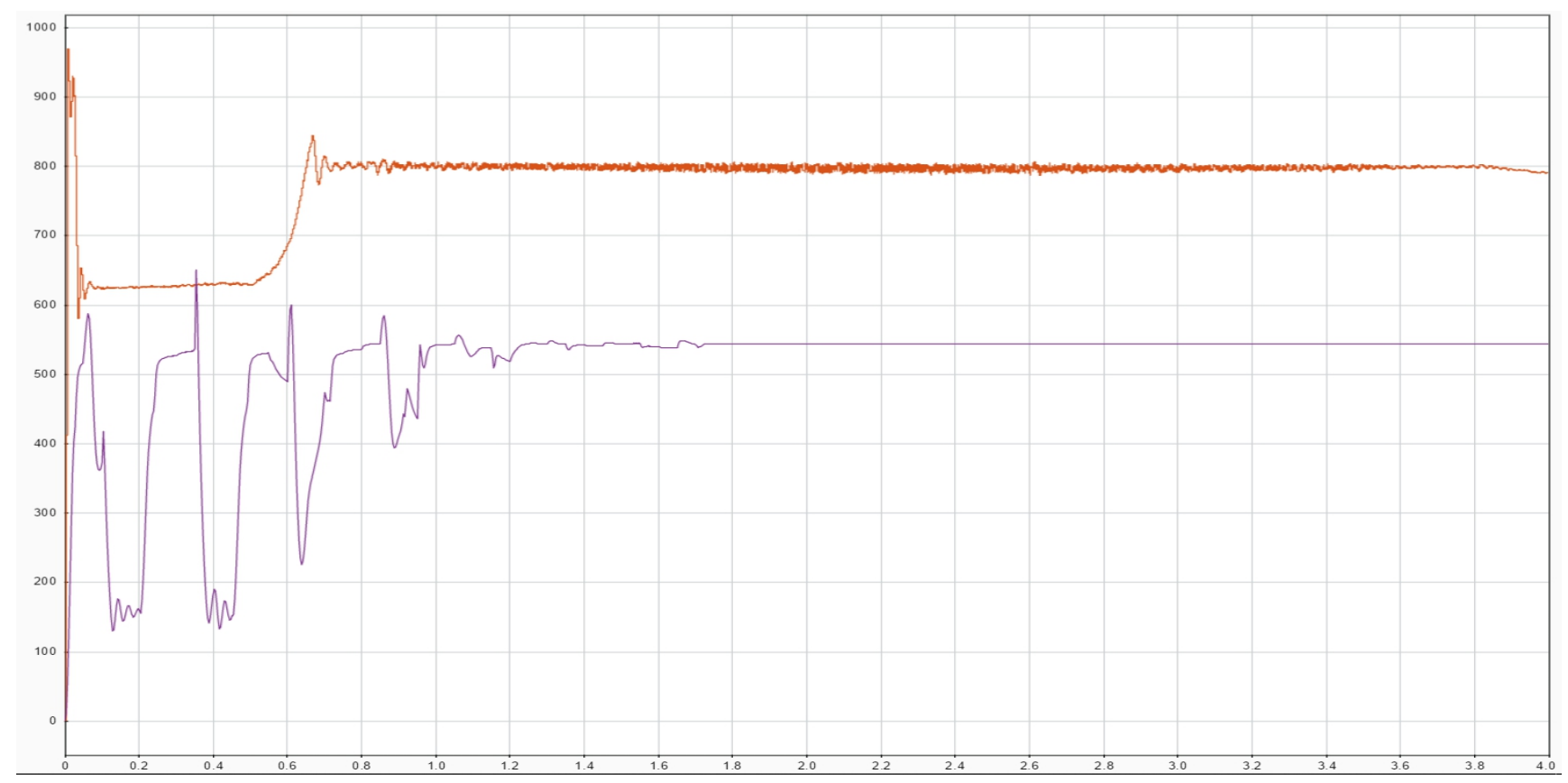

Fig 47: Output boost voltage results for PSO and P\&O based PV System.

\subsection{Comparative Results of PSO and P\&O based PV System for Current}

The figure 56 represents the PV current graph comparision for PSO based PV system and P\&O based PV system where the blue line represents the P\&O based current output and the red line represents the PSO based current output for PV systems. There is less deviation in PSO based current output for PV system as compare to the P\&O based PV system and this can be reduced further by changing in algorithm.

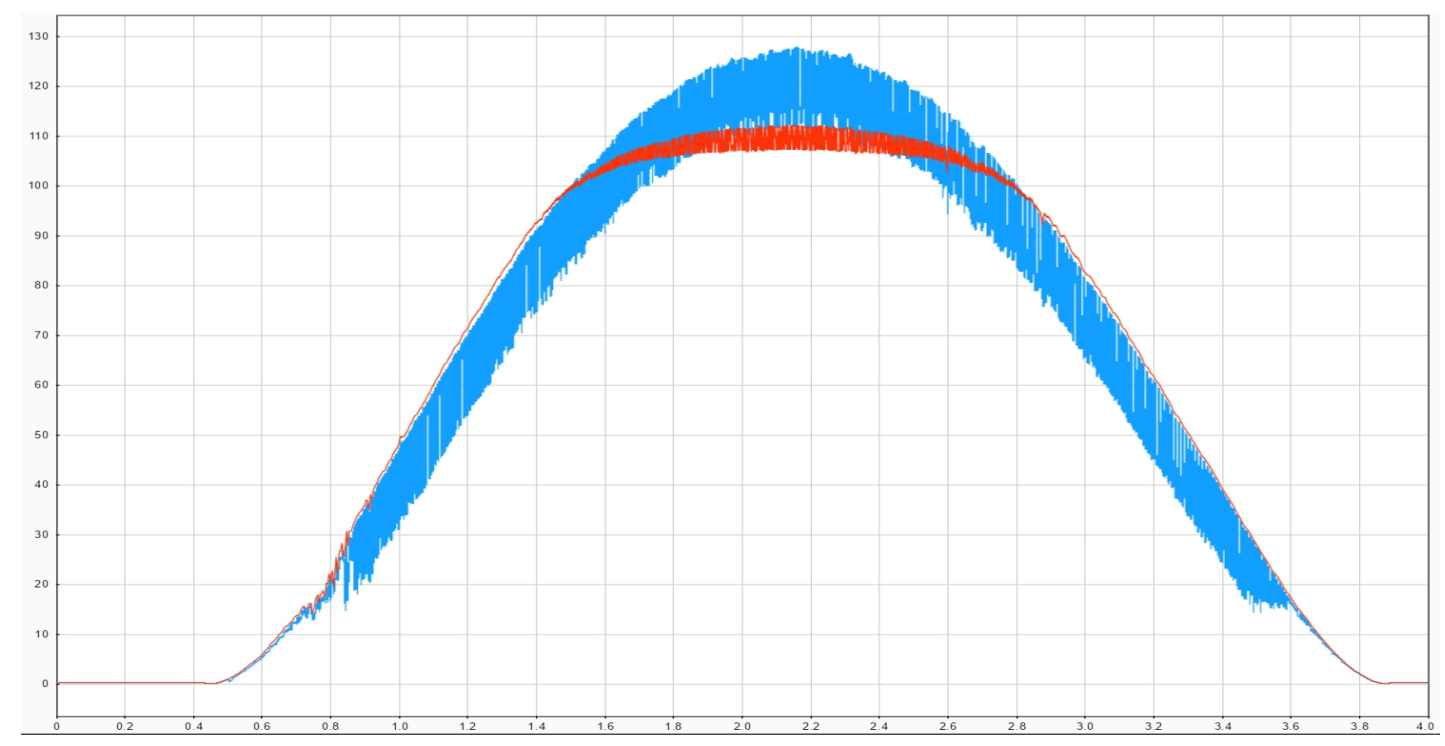

Fig 48: Output current results for PSO and P\&O based PV System. 
Here the rede line represents the power output for P\&O PV system with high voltage deviation and PSO based PV system power output values are slightly less than the P\&O based dual stage PV system. The particular reason behind that is reduction of current output in PSO based PV system, and this current reduction is dependent on the PSO algorithm used and if we improve this algorithm then we can get better current and power output results.

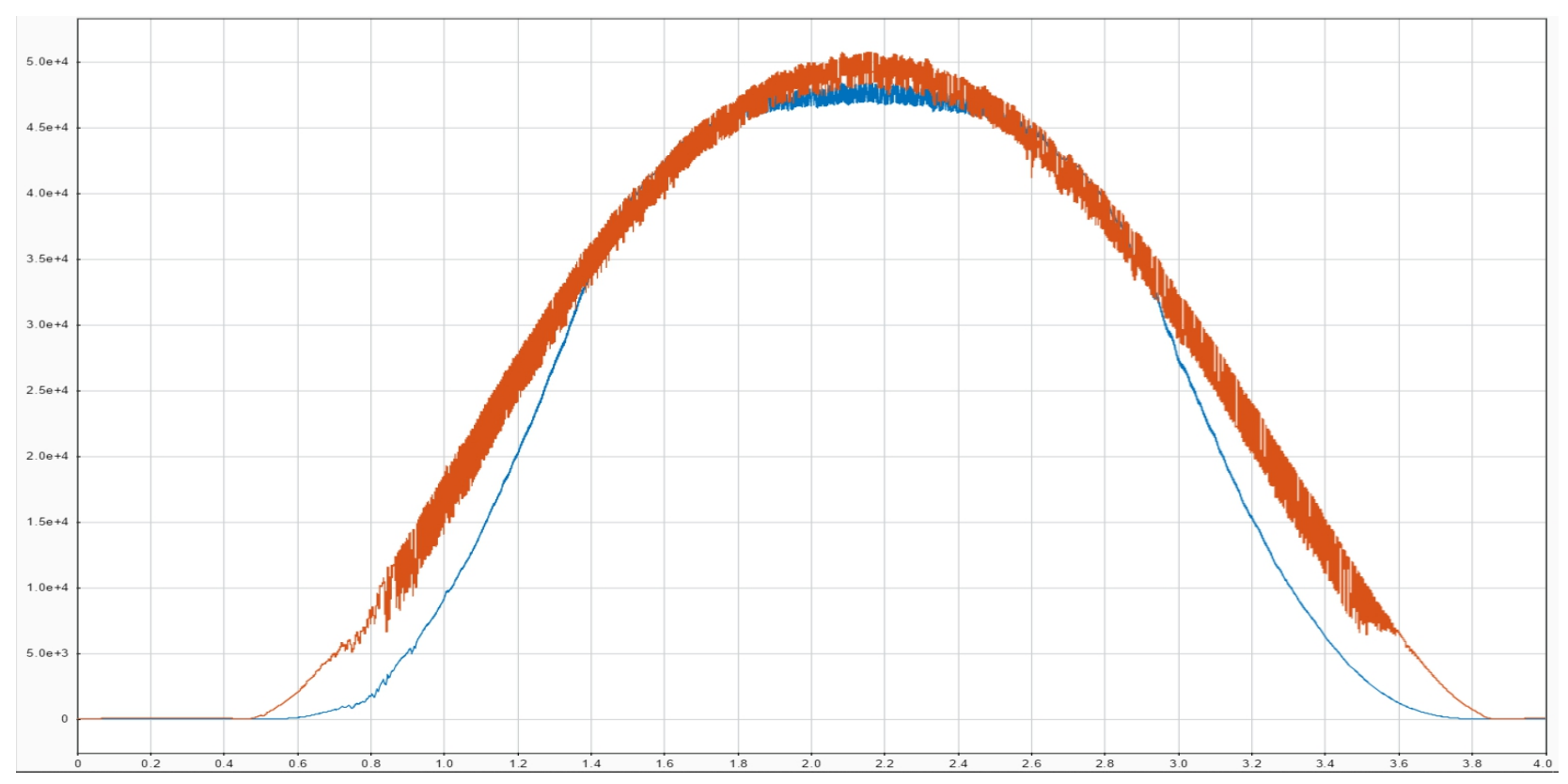

Fig 49: Output Power results for PSO and P\&O based PV System.

\section{CONCLUSION}

The beat signal was generated using a PWM generator, and then compared to the signal from the MPPT unit, which was utilized to transmit the gating signal to the switch. The customer would have had to manually enter the obligation cycle into the system if MPPT had not been implemented. When the solar powered light changes, the maximum force point changes as well, and the necessary obligation cycle for the model's activity changes as well. However, if a steady obligation cycle is used, the most severe force point cannot be tracked, and the framework becomes less effective. The plot tool in MATLAB was used to obtain the various waveforms. From the sun-based board to the lift converter yield side, there is a slight decrease of intensity. This can be attributed to the support converter's inductor and capacitor exchanging misfortunes and misfortunes. The parameters of the inverter model, such as inductance, dc gain (kv), and time constant (television), have a considerable influence on the framework elements during the exchanging time, and should be carefully selected to produce a stable intermittent conduct. For single stage signals, a Linear PLL (LPLL) is used with good results, whereas for 3-stage adjusted signals, a Synchronous Reference Frame (SRF) PLL is used. In any case, because the recognized stage point comprises second symphonious movements, it can't be used for unequal utility conditions.

When comparing the two topologies, it is clear that

1) Single stage topology is efficient but costs more.

2) Better DC Voltage Stability and AC Side Voltage THD using a two-stage architecture 
3) MPPT accuracy: both can satisfy accuracy requirements within an acceptable error range of controller oscillation and ac filter loss.

Particle Swarm Optimization is a simple and effective meta-heuristic technique to nonconventional intelligence optimization and Finally, when compared to the classic MPPT-P\&O approach and other PSO-based MPPT algorithms, the MPPT-PSO technique exhibited the best performance.

\section{References}

1. Hannah Ritchie "Electricity is only one part of total energy- decarbonizing electricity is only one step towards a low-carbon energy system”, Energy Mix 2021.

2. Efficiency chart for different kind of Solar Modules by National Renewable Energy Laboratory.

3. K.H. Hussein, I. Muta, T. Hoshino and M. Osakada, "Maximum photovoltaic power tracking:an algorithm for rapidly changing atmospheric conditions,"IEEEploc.-Gener. Transmission and Distribution

4. Villalva, Marcelo Gradella, and Jonas Rafael Gazoli. "Comprehensive approach to modeling and simulation of photovoltaic arrays." Power Electronics, IEEE Transactions on 24.5, 2019 pp. 1198-1208.

5. Sridhar, R., et al. "Modeling of PV array and performance enhancement by MPPT algorithm." Int J Comput Appl 7.5: 2018, pp. 35-39.

6. E. Vartiainen, "A new approach to estimating the diffuse irradiance on inclined surfaces,"Renewable Energy, Vol. 20, 2014.

7. H. Fujita, "A three-phase voltage-source solar power conditioner using a single-phase PWM control method," in Proc. of IEEE Energy Conversion Congress and Exposition, 2017, pp. 3748-3754.

8. Santosh S. Raghuwanshi, Kamlesh Gupta," Modeling of a Single Phase Grid-Connected Photovoltaic System Using MATLAB/Simulink", IEEE International Conference on Computer, Communication and Control -2015.

9. Parimita Mohanty et al., "MATLAB Based Modeling to Study the Performance of Different MPPT Techniques Used for Solar PV System Under Various Operating Conditions," Elsevier, Renewal and Sustainable Energy Reviews 38 (2014) 581- 893.

10. S. Yuvarajan "Performance ratio - Quality factor for the PV plant", SMA, SMA Technical Information, 2018, pp $1-9$.

11. Prof.Dr.IlhamiColak, Dr.ErsanKabalci and Prof.Dr.GungorBal, "Parallel DC AC Conversion System Based on Separate Solar Farms with MPPT Control," 8th International Conference on Power Electronics ECCE Asia, The ShillaJeju, Korea, May 30-June 3, 2011.

12. C.Thulasiyammal and S Sutha, "An Efficient Method of MPPT Tracking System of a Solar Powered Uninterruptible Power Supply Application," 1st International Conference on Electrical Energy Systems, 2011.

13. Jaydeep,V. Ramoliya , " Perfonnance Evaluation of Grid-connected Solar Photovoltaic plant using PVsyst Software", February 2015, Volume 2, Issue 2 J ETIR (1SSN-2349-5162). 
14. N.M. Kumar, M.R. Kumar, P.R. Rejoice and M. Mathew, "Performance analysis of $100 \mathrm{kWp}$ grid connected Si-poly photovoltaic system using PVsyst simulation tool", Energy Procedia, Elsevier, 2017, vol. 117 , pp $180-189$.

15. Calais, Martina, et al. "Inverters for single-phase grid connected photovoltaic systems-an overview." Power Electronics Specialists Conference, 2012. pesc 02. 2012 IEEE 33rd Annual. Vol. 4. IEEE, 2012.

16. Mohamed Azab "Optimization of Perturb and Observe Maximum Power Point Tracking Method," IEEE Transactions On Power Electronics, Vol. 20, No. 4, July 2015.

17. Ashish Pandey, Nivedita Das Gupta and Ashok Kumar Mukerjee, "High-Performance Algorithms for Drift Avoidance and Fast Tracking in Solar MPPT System," IEEE Transactions on Energy Conversion, Vol. 23, No. 2, June 2008.

18. Yang Du and Dylan Dah-Chuan Lu, "Analysis of a Battery-Integrated Boost Converter for Module-Based Series Connected Photovoltaic System," The International Power Electronics Conference, 2010.

19. Wafa Hayder et al., "Improved PSO: A Comparative Study in MPPT Algorithm for PV System Control under Partial Shading Conditions", 2020 MDPI Journal of Energies.

20. Yao Z Q, Zhang Q, Liu X M. Research on simulation of a three-phase grid-connected photovoltaic generation system based on PSCAD/EMTDC. Power System Protection and Control, 2010, 38(17): 76-81

21. Dorofte C, Borup U, Blaabjerg F. A combined two-method MPPT control scheme for grid-connected photovoltaic systems. European Conference on Power Electronics and Applications, 2005: $10 \mathrm{pp}$

22. ZHU YangLi, Yao JianGuo, Wu Di , Comparative study of two stages and single stage topologies for Grid-Tie Photovoltaic Generation by PSCAD/EMTDC, 2011The International Conference on Advanced Power System Automation and Protection.

23. K. Ishaque, Z. Salam, M. Amjad and S. Mekhilef, "An improved particle swarm optimization (PSO)-Based MPPT for PV with reduced steadystate oscillation," 2012, IEEE Transactions Pages. 3627-3638. 